\title{
Shear strengthening of reinforced concrete beams with Hybrid Composite Plates (HCP) technique: Experimental research and analytical model
}

\author{
Hadi Baghi ${ }^{1}$, Joaquim A. O. Barros² ${ }^{2}$ Fatmir Menkulasi ${ }^{3}$
}

\author{
${ }^{1}$ Post-doc, Civil Engineering and Construction Engineering Technology, Louisiana Tech University, Ruston, U.S., \\ 71272-0046, e-mail: hadibaghi@gmail.com (corresponding author). \\ ${ }^{2}$ Full Professor, ISISE, Department of Civil Engineering, University of Minho, Guimarães, Portugal, \\ e-mail: barros@civil.uminho.pt. \\ ${ }^{3}$ Assistant Professor, Civil Engineering and Construction Engineering Technology Louisiana Tech University, \\ Louisiana, USA; e-mail: fmenkula@latech.edu.
}

\begin{abstract}
This paper presents a study on the efficiency of Hybrid Composite Plates (HCPs) in enhancing the shear strength and stiffness of reinforced concrete (RC) beams. HCP is a thin plate of Strain Hardening Cementitious Composite (SHCC) reinforced with Carbon Fiber Reinforced Polymer (CFRP) laminates applied to the sides of reinforced concrete beams according to the Near Surface Mounted technique (NSM). Due to the excellent bond conditions between SHCC and CFRP laminates, these reinforcements provide the necessary tensile strength capacity to the HCP. To examine the efficiency of HCPs as a shear strengthening technique, a total of $17 \mathrm{RC}$ beams are tested. Seven of these beams have a rectangular cross-section and ten have a $\mathrm{T}$ cross-section. The influence of the percentage and inclination of the CFRP laminates on the shear strengthening effectiveness of HCPs is investigated. Two different processes for applying the HCPs to the beams' concrete substrate are examined: 1) using epoxy adhesive; and 2) using mechanical anchors in addition to the epoxy adhesive. It is demonstrated that when only epoxy adhesive is used, the shear strengthening contribution of the HCPs is limited by the tensile strength of the concrete substrate of the strengthened beams. When mechanical anchors are applied in addition to the epoxy adhesive, the shear strengthening potential of HCPs is fully mobilized. An analytical model is proposed to predict the shear strength of RC beams strengthened with HCPs. It is demonstrated that the analytical model predicts with good accuracy the shear strength of RC beams strengthened with HCPs.
\end{abstract}


Keywords: Hybrid Composite Plate; CFRP laminates; Shear strengthening; Simplified Modified Compression Field Theory.

\section{Introduction}

Application of the Fiber Reinforced Polymer (FRP) materials by using externally bonded reinforcement (EBR) or near surface mounted (NSM) techniques have been extensively studied for the shear strengthening of reinforced concrete (RC) structures [1-9]. Based on the results in the literature [2, 4, 8], debonding in case of the EBR technique, and debonding with concrete fracture in the NSM technique [9, 10], avoid the full exploitation of the strengthening potential of FRP materials. The use of anchors systems can prevent or delay these types of failure modes [2, 3, 7, 11, 12], however, the application of these systems requires extra time and costs, and can be susceptible to vandalism acts and the detrimental effect of environmental agents. Special CFRP laminates, capable of being fixed with anchor devices without premature local rupture in the anchor zones, have been proposed, but these composites are more expensive than current CFRP systems $[12,13]$. Lack of protection against vandalism and fire, quality of concrete substrate, and surface preparation are also some drawbacks of these techniques [4].

Recently, thin plates of Strain Hardening Cementitious Composites (SHCC) with CFRP laminates have been used to increase the flexural capacity of the RC beams and also the energy dissipation of beam-column joints [14-16]. This strengthening technique is called Hybrid Composite Plate (HCP). SHCC materials exhibit ductile shear response, high energy absorption capacity, stable hysteretic loops at large drifts, and ensure structural integrity [17-19]. To bond the CFRP laminates into the SHCC plate, slits are opened on the surface of the plate and CFRP laminates are inserted into these slits and bonded to the surrounding SHCC with an appropriate epoxy adhesive [16]. The HCPs are bonded to the lateral faces of the beams using epoxy adhesive or a combination of bonded epoxy adhesive and mechanical anchors (Figure 1). The mechanical anchors prevent premature debonding of the HCPs, and provide a certain level of concrete confinement in the strengthened zone of the beam, leading to favorable effects in terms of shear strengthening effectiveness. In addition to enhancing the strengthening efficiency of HCPs, the SHCC also assures some protection to the CFRP laminates and adhesive with respect to accidental actions, such as vandalism, aggressive environmental conditions, and fire.

In this study, the influence of the HCPs on shear strengthening and repairing of RC beams is assessed by executing an extensive experimental program. This paper also investigates: 
- The influence of the orientation of the CFRP laminates that reinforce the SHCC plate;

- The influence of the CFRP shear strengthening ratio;

- The influence of using mechanical anchors to install the HCPs;

- The effectiveness of HCP for shear repairing of damaged RC beams;

A detailed description of the executed experimental research and a discussion of the obtained results are presented. An analytical formulation is developed to predict the shear capacity of the beams strengthened with HCPs. The new approach combines the Simplified Modified Compression Field Theory [20] (SMCFT) with the model developed by Bianco et al. [10] and it considers the relevant features of the interaction between NSM FRP systems, SHCC, and concrete. The analytical formulation is described and its predictive performance is assessed.

\section{Research Significance}

An experimental program is executed to demonstrate the effectiveness of the Hybrid Composite Plates (HCPs) for shear strengthening of reinforced concrete beams. The new technique aims to overcome the shortcomings of the EBR and NSM techniques, such as: debonding of the FRP, lack of protection (vandalism and fire), and stress concentration caused by anchorage devices when used for avoiding the premature debonding of the FRP. Additionally, this research investigates the shear strengthening effectiveness of the orientation and percentage of CFRP laminates, as well as the use of mechanical anchors for installing the HCPs. The effectiveness of this technique for the shear strengthening of damaged RC beams is also explored. An analytical approach is developed combining the Modified Compression Field Theory (MCFT) with the Bianco et al. model to predict the shear capacity of RC beams strengthened with this new technique.

\section{Experimental program}

The experimental program consists of testing two series of beams, the first one (Series A) composed of seven beams with a rectangular cross-section (Figure 2), and the second (Series B) is formed by ten beams with a T cross section (Figure 3). All beams were used in a single span simply supported configuration. To induce shear failure in only one span, a three point bending test setup of different shear span lengths was adopted. In rectangular and T cross section beams the length of monitored shear span, $a$, was 3.0 and 2.5 times the effective depth of beams, $d$, respectively. The reinforcing was designed to obtain a shear failure mode in all tested beams except R-7S-R beam. This beam was 
designed to fail in flexure to measure the flexural capacity of the rectangular cross section beams. The geometry of the beams was considered representative of real scale beams. The flange reinforcing in $\mathrm{T}$ cross section beams consisted of typical slab reinforcing. A relatively high shear reinforcement was applied in the other span $\left(L_{r}\right)$ for avoiding shear failure in this span ( $\phi 8 @ 100 \mathrm{~mm}$ in series A and $\phi 6 @ 75 \mathrm{~mm}$ in series B). The characteristics of the tested beams are presented in Table 1. To distinguish the strengthened beams with HCP from the other beams (R-C-R, T-C-R, RNSM-4L90, T-NMS-3L45, R-SP, T-SP, R-7S-R, and T-7S-R beams), the R/T-D-NL45/90-B/BC designation was adopted, where $\mathrm{R} / \mathrm{T}$ means a rectangular $(\mathrm{R})$ or $\mathrm{T}$ cross section beam, $\mathrm{D}$ (where applicable) indicates a damaged beam, $\mathrm{N}$ means the number of the CFRP laminates (L) with $45^{\circ}$ or $90^{\circ}$ inclination, B (where applicable) indicates that the HCP was bonded and anchored by mechanical bolts (B), and BC (where applicable) means that a connection between the flange and the web was used. The R-7S-R and T-7S-R beams (Figure 2a and 3a) had $\phi 8 @ 100 \mathrm{~mm}$ and $\phi 6 @ 112.5$ $\mathrm{mm}$ in the monitored shear span, respectively, while the other beams of both series (Figure $2 \mathrm{~b}$ and $3 \mathrm{~b}$ ) did not include steel stirrups in $L_{i}$ shear span.

The R-C-R and T-C-R were control beams without shear reinforcement throughout the $L_{i}$ span. In the first step, the control beams were loaded up to failure load, and then fully unloaded. In the next step these beams were repaired by applying the HCPs to each lateral face of the monitored shear span using a combination of epoxy adhesive and mechanical anchors. The repaired beams, designated as R-D-3L45-B and T-D-5L45-BC, were subjected to the same test configuration adopted in their undamaged state.

The R-NSM-4L90 and T-NSM-3L45 were beams without steel stirrups in $L_{i}$ span and were strengthened according to the NSM technique with 4 vertical $\left(\theta=90^{\circ}\right)$ and 3 inclined CFRP laminates $\left(\theta=45^{\circ}\right)$, respectively, in each lateral face of $L_{i}$ span (Figures $4 \mathrm{a}$ and $5 \mathrm{a}$ ). The R-SP and T-SP were beams strengthened with SHCC plates to study the effectiveness of these plates for the shear strengthening (Figures $4 b$ and $5 b$ ).

The strengthened beams with HCPs (R-4L90, R-3L45, T-3L45, T-3L45-B, T-5L45, T-5L45-B, and T-5L-BC) were designed to assure that the load carrying capacity was similar to the corresponding beams with seven steel stirrups in the monitored shear span (R-7S-R and T-7S-R beams) (Figures 4 and 5). To prevent the localization of failure in webflange transition zone, the T-5L-BC and T-D-5L-BC beams were also strengthened with 4 steel bars connectors (Figures 5g and 5h). 
The load was applied monotonically by means of a closed-loop servo-controlled hydraulic actuator. The tests were executed in displacement control at a rate of $0.01 \mathrm{~mm} / \mathrm{s}$. The deflection of the beams was measured with one Linear Variable Differential Transducer (LVDT) located in the loaded section. To obtain the strain variation in the laminates, strain gages were bonded to the CFRP laminates according to the arrangement represented in Figure 4 and 5.

The average values obtained from the experimental programs for the assessment of the relevant material properties of concrete, CFRP laminates, SHCC, and reinforcing steel are presented in Tables 2 and 3. The concrete compressive strength was evaluated at the age of the beam tests, by carrying out direct compression tests with cylinders of $150 \mathrm{~mm}$ diameter and $300 \mathrm{~mm}$ height according to EN-206-1 [21]. To assess the tensile behavior of the steel bars, uniaxial tensile tests were carried out according to EN10002-1 recommendations [22]. The tensile properties of the CFRP laminates were characterized by executing uniaxial tensile tests according to the recommendations of ISO 527-5 [23]. The SHCC is composed of a cementitious mortar reinforced with $2 \%$ in volume of short discrete polyvinyl alcohol (PVA) fibers of $40 \mu \mathrm{m}$ diameter and $8 \mathrm{~mm}$ length. The envelope and the average tensile stress versus crack opening displacement (COD) obtained in notched specimens are presented in Figure 6. More information about the mix composition, curing process and experimental characterization of the SHCC can be found in [24].

The HCP in this experimental program was a $20 \mathrm{~mm}$ thick SHCC plate reinforced with CFRP laminates applied at $90^{\circ}$ and $45^{\circ}$ according to the procedures of the NSM technique [9]. To apply the HCPs to the lateral faces of the concrete beams, the following procedures were followed:

1) A sandblasted roughened surface was created in the concrete substrate to improve the bond between the HCPs and the concrete substrate;

2) Holes were drilled through the web of the beams (Figure 4e, 5g, and 5h) with a diameter of $12 \mathrm{~mm}$ ( 2 mm bigger than the diameter of the bolt) for the installation of the mechanical anchors in the beams that HPCs were bonded and fixed using adhesive and mechanical anchors;

3) An $1 \mathrm{~mm}$ thick epoxy adhesive layer was homogenously applied on the surfaces of the concrete beam and on the contact surface of the HCP;

4) In the beams without anchors, mechanical clamps were used to maintain the HPCs pressed against the lateral surfaces of the beam until the epoxy resin developed almost its full tensile strength capacity (approximately 2 days); 
5) In beams that featured anchors, the HCPs were fixed to the concrete substrate with anchors composed of bolts and nuts, by applying a torque of 20 N.m in the nuts on both sides of the beams. According to Figure 7 and Eq. (1), the applied torque can be converted to axial load.

$$
F=\frac{\tau}{r}
$$

where $F$ is the axial load, $\tau$ is the applied torque, and $r$ is the radius of the bolt. More information about the strengthening technique of these beams can be found in [16].

\section{Results}

\section{Load carrying capacity of the tested beams}

The relationship between applied load and deflection at loaded section for the rectangular and $\mathrm{T}$ cross section beams are presented in Figures 8a and 8b, respectively. For deflections higher than the one corresponding to the formation of the first shear crack in the strengthened beams with NSM techniques, a $\Delta F / F^{N S M}$ ratio was calculated, where $\Delta F^{N S M}$ is the increase in the load provided by HCPs $\left(\Delta F=F-F^{N S M}\right), F^{N S M}$ is the load capacity of the beam strengthened with NSM CFRP laminates, and $F$ is the corresponding load capacity (for the same deflection) of the beams strengthened with HCPs. The relationship between $\Delta F / F^{N S M}$ ratios and the corresponding deflection for the rectangular and $\mathrm{T}$ cross section beams are depicted in Figures 9a and 9b, respectively. The maximum load and the corresponding deflection, the maximum $\left(\Delta F / F^{N S M}\right)_{\max }$ ratio, and the failure modes for all tested beams are presented in Table 4 . The values of the $F_{\max } / F_{\max }^{7 S-R}$ ratio are also presented in this table, which is the ratio between the maximum load capacity of the beam strengthened with HCPs $\left(F_{\max }\right)$ and its corresponding value in the beam with seven steel stirrups (R-7S-R and T-7S-R beams) in monitored shear span $\left(F_{\max }^{7 S-R}\right)$.

The results provided in Table 4 and illustrated in Figures 8 and 9 show that for deflections higher than the one corresponding to the formation of the first shear crack in the strengthened beams with NSM, HCPs provided an increase in the beams' load carrying capacity. In fact, the decrease of stiffness observed in the strengthened beams with NSM when the first shear crack was formed was not so significant in the strengthened beams with HCPs. 
By comparing the results of the strengthened beams with HCPs with those determined in the corresponding beams strengthened with SHCC plate (R-SP and T-SP) it is shown that the CFRP laminates have contributed to the higher shear strengthening effectiveness of HCPs, since the laminates have avoided the degeneration of the micro-cracks in the SHCC plates on macro-cracks, which has a positive effect in terms of the stiffness preservation of the beams. In rectangular cross section beams, the results show that the shear strengthening configuration provided by HCPs including CFRP laminates at $45^{\circ}$ (R-3L45 and R-D-3L45-B) was the most effective in terms of maximum load carrying capacity, since an increase of $105 \%$ and $98 \%$ were obtained compared to R-C-R beams, while an increase of 87\%, 77\%, and 60\% were determined for R-4L90, R-NSM-4L90, and R-SP beams, respectively.

As shown in Figure 9b, the load of the T-5L45-B beam at a deflection of about $15 \mathrm{~mm}$ is around $125 \%$ higher than the load of the T-NSM-3L45 beam. Also, the increase of the load provided by the HCPs $\left(\Delta F / F^{N S M}\right)_{\max }$ in T-5L45BC beam at maximum load is around 348\% higher than T-NSM-3L45 beam. These results show the effectiveness of the HCPs and mechanical anchors in terms of post peak load and deformation capacity. In fact, with the exception of T-5L45 beam, the post-peak performance of the beams shear strengthened with HCPs is much higher than the performance of the T-NSM-3L45 beam.

The obtained experimental results show that in the series A the strengthened beams with HCPs (with or without damage) had a maximum load of $91 \%$ and $88 \%$ of the maximum load of the R-7S-R beam, respectively, and in the series B the maximum load of the T-5L45-BC and T-D-5L45-BC beams were 104\% and 100\% of the T-7S-R beam, respectively.

In R-D-3L45-B and T-D-5L45-BC beams, in spite of the significant damage induced in the R-C-R and T-C-R beams during testing, the stiffness of these beams was even higher than the corresponding beams without damage (R-3L45 and T-5L45-BC beams) (Figures 8a and 8b), which means that the strengthening technique used in these beams was able to exceed the stiffness of the R-3L45 and T-5L45-BC beams.

\section{Failure modes}

Figures 10 and 11 represent the crack patterns at failure of the rectangular and T cross section beams, respectively. As expected, all the tested beams failed in shear, with the exception of the R-7S-R beam that failed in flexure. The R-C$\mathrm{R}$ beam failed in shear with an abrupt load decay just after the peak load (Figure 10a). In the T-C-R beam, two cracks formed at a load of about $100 \mathrm{kN}$, one at the support section and another one at the center of the beam. In this beam, 
the cracks widened and propagated as the load was increased to $214 \mathrm{kN}$. At this load level the beam failed at the support section before shear failure of the beam occurred. As shown in Figure 11a by an ellipse, at failure load the critical shear crack was formed, however it did not degenerate in a shear failure crack due to inadequate anchorage of longitudinal reinforcing at the support. Hence, to improve the anchorage conditions of the longitudinal reinforcement of T-C-R beam and other T cross section beams, a strengthening system based on the use of longitudinal NSM CFRP laminates of $1.4 \times 20 \mathrm{~mm}^{2}$ cross section and with a total length of $400 \mathrm{~mm}$ was applied on the bottom face of the beams, as illustrated in Figure 5.

As mentioned before, the R-7S-R beam failed in bending with the yielding of the flexural reinforcement, followed by concrete crushing at mid-span (Figure 10b). The T-7S-R beam presented a brittle shear behavior, with an abrupt load decay at peak load, which is justified by the relatively high shear reinforcement ratio. Figure $11 \mathrm{~b}$ presents the final crack pattern of T-7S-R beam. As shown in Figure 8b, after this abrupt load decay, the load was stabilized at a level of about $100 \mathrm{kN}$, which almost corresponds to the shear resistance assured by the longitudinal bars due to dowel effect, obtained according to the CEB-FIP Model Code 2010 [25].

Both strengthened beams with SHCC plate (R-SP and T-SP beams) failed in shear (Figure 10c and 11c). The shear resistance of these two beams was around $60 \%$ and $19 \%$ higher than the corresponding reference beams, respectively. Both beams presented a brittle behavior, with an abrupt load decay at peak load. The fibers in SHCC panel were not able to absorb and sustain the significant amount of energy released during the formation of critical shear cracks. In the beams strengthened with the NSM technique (R-NSM-4L90 and T-NSM-3L45) the increase in load caused the formation of some cracks around the middle laminates. Once the shear capacity of the middle laminates was exhausted, a sudden failure occurred with the widening of the shear crack (Figure 10d and 11d).

In the beams strengthened with HCPs applied exclusively with epoxy adhesive (R-4L90, R-3L45, T-3L45, and T5L45) the failure mode was governed by the detachment of the HCPs (Figures 10e, 10f, 11e, and 11g). At failure, with the exception of the T-5L45 beam, a concrete cover layer of an average thickness that varied between 5 to $10 \mathrm{~mm}$ was attached to the HCPs and separated from the rest of the beam. This indicates that to better mobilize the strengthening potential of the CFRP laminates, the HCPs should not only be bonded to the substrate with an adhesive, but also fixed by using mechanical anchors.

In T-5L45-B and T-3L45-B beams the HCPs were bonded to the lateral faces of the beams using epoxy adhesive and mechanical anchors (Figure 5d and 5f). While the T-3L45-B failed in shear with an abrupt load decay at peak load, in 
the T-5L45-B beam, the reinforcement effectiveness of the CFRP laminates avoided the degeneration of the microcracks into macro-shear failure cracks on the SHCC, and the mechanical anchors prevented the premature detachment of the HCPs, and the failure was localized at the web-flange zone of the beam due to a strength discontinuity in that area, considering that no internal stirrups were available to offer resistance to the propagation of this type of failure crack. It is visible that in the post-peak stage of the T-5L45-B beam, the load decay was much smoother, and the residual load carrying capacity of this beam was much higher than the one registered in the T-3L45-B beam, due to the larger fracture surface mobilized in the failure mode of the T-5L45-B beam.

As previously mentioned, due to excellent bond conditions between SHCC and CFRP laminates, this reinforcement provided the necessary tensile strength capacity to the HCP, while the high post-cracking tensile deformability and resistance of the SHCC avoided the occurrence of premature fracture failure of this cement composite in the stress transfer process between these two materials when the HCP was crossed by the shear cracks formed in the RC beam (existing crack in case of damaged beams). Due to this effect, the failure crack of R-D-3L45-B beam was localized at the zone of the HCPs without any CFRP laminate (Figure 10g). The failure of this beam was governed by local detachment and shear failure.

To preclude the crack propagation through the web-flange zone (a type of failure observed in the T-5L45-B beam), steel bars were applied to the T-5L45-BC and T-D-5L45-BC beams, as shown in Figure 5g and 5h, respectively. The failure mode in these two beams presents more micro cracks on the surface of the HCPs (Figure 11i and 11j) than in the previous beams due to the ability of the bonded and anchored SHCC to preclude the propagation of the exiting crack, and to more efficiently contribute in enhancing the shear capacity of the reinforced concrete beams. This is not clearly shown in the photographs because the cracks have small width (micro-cracks). The steel bar connectors applied in these beams avoided the occurrence of the premature failure at the web-flange zone, observed in the T-5L45-B beam, and the failure of these beams were governed by shear.

\section{Strains in the CFRP laminates}

Figure 12 shows the relationship between the applied load and the measured strain in CFRP laminates. Up to the formation of the shear crack the maximum strain increased almost linearly with the applied load, but did not exceed the strain value of $0.01 \%$ demonstrating that these CFRP laminates had marginal shear strengthening contribution during this stage, as expected. However, after the formation of the shear crack, an abrupt increase in strain occurred. 
The strains recorded by SGs during the loading of the repaired beams (R-D-3L45-B and T-D-5L45-BC) were different than those measured in the beams without damage, since the CFRP laminates were sooner mobilized in the damaged beams because they were placed crossing the existing crack, and the SGs were placed quite close to this crack (Figures 4e and 5h). When the load was increased, the major shear crack on the damaged beams started widening and a higher gradient of strain was registered.

Due to the premature detachment of the HCPs in the beams without mechanical anchors, the CFRP laminates were not mobilized effectively. In fact, higher tensile strains in CFRP laminates were recorded in the beams strengthened with HCPs fixed with both adhesive and mechanical anchors. The maximum tensile strain of $1.8 \%$ was recorded in T5L45-BC beam (Figure 12b), which is equal to the ultimate tensile strain of the CFRP laminates, indicating that this laminate was almost in its rupture stage.

\section{Analytical Formulation}

\section{Simplified Modified Compression Field Theory}

Compression Field Theory (CFT) was developed to predict the shear capacity of RC members. In this model it is assumed that, after cracking, the concrete does not resist tension, and the shear is resisted by a field of diagonal compressive stresses. Since the CFT neglects the resistance of cracked concrete in tension, the shear strength is generally estimated conservatively [26]. The Modified Compression Field Theory (MCFT) is an enhancement of the CFT, since it takes into account the contribution of the cracked concrete in tension [20].

Vecchio and Collins [20] found that the principal compressive stress was not only a function of the principal compressive strain, but also of the corresponding transversal principal tensile strain. They also verified that after the formation of diagonal cracking, tensile stresses still exist in the concrete between cracks. Combined with shear stresses on the crack faces, these tensile stresses are supposed to increase the ability of the cracked concrete to resist shear. This theory was used to predict the shear strength of 102 panels tested experimentally. The average ratio between experimental and analytical results was 1.01, and the coefficient of variation (COV) was $12.2 \%$ [27]. Nevertheless, solving the equations of the MCFT requires an iterative procedure and the knowledge of a relatively high number of parameters, which introduces some difficulties from the designer's perspective. 
Bentz et al. [27] suggested a simplified approach of the MCFT method (SMCFT). In this model, the shear strength of a section is a function of two parameters: the tensile stress factor in the cracked concrete $(\beta)$ (Eq. (2)), and the inclination of the diagonal compressive stress in the web of the section $(\theta)$ (Eq. (3)).

$$
\begin{aligned}
& \beta=\frac{0.4}{1+1500 \varepsilon_{x}} \cdot \frac{1300}{1000+s_{x e}} \\
& \theta=\left(29+7000 \varepsilon_{\mathrm{x}}\right) \cdot\left(0.88+\frac{\mathrm{s}_{\mathrm{xe}}}{2500}\right) \leq 75^{\circ}
\end{aligned}
$$

where $\varepsilon_{x}$ and $s_{x e}$ are longitudinal strain and crack spacing parameter, respectively, and can be determined by Eq. (4) and Eq. (5), respectively:

$$
\begin{aligned}
& \varepsilon_{x}=\frac{f_{s x}}{E_{s}}=\frac{v \cdot \cot \theta-v_{c} / \cot \theta}{E_{s} \rho_{s x}} \\
& s_{x e}=\frac{35 s_{x}}{a_{g}+16} \geq 0.85 s_{x}
\end{aligned}
$$

where $s_{x}, a_{g}, E_{s}, \rho_{s x}, v_{c}$, and $v$ are vertical distance between longitudinal reinforcement, maximum aggregate size, modulus of elasticity of longitudinal reinforcement, longitudinal steel reinforcement ratio, shear strength due to concrete, and shear strength of a RC beam, respectively. In Simplified MCFT, the shear strength of a RC beam is determined by the following equation:

$$
v=v_{c}+v_{s}=\beta \sqrt{f_{c}^{\prime}}+\rho_{y} f_{y \text { yield }} \cot \theta
$$

where $v_{s}$ is the shear strength provided by steel stirrups. Additionally, $f_{c}^{\prime}, \rho_{y}$, and $f_{y \text { yield }}$ are the compressive strength of concrete, transverse steel reinforcement ratio, and yield stress in transverse steel reinforcement, respectively. In spite of the simple format of the equations for $\beta$ and $\theta$, the method generally provides excellent predictions of shear strength of RC beams. The average ratio of experimental to predicted shear strength using the SMCFT for 102 RC elements was 1.11 with a COV of $13.0 \%$ [27].

\section{Bianco et al. Approach}

Bianco et al. $[10,28,29]$ proposed a 3D mechanical model to predict the shear strength contribution of NSM CFRP laminates (Figure 13). The following paragraphs summarize the formulation of this approach: 
Step 1: Provide input parameters: beam cross section $\left(h_{w}, b_{w}\right)$, inclination of the critical diagonal crack (CDC) and NSM FRP laminates $\left(\theta, \theta_{f}\right)$, horizontal spacing of NSM FRP laminates $s_{f}$, angle $\alpha$ between axis and principal generatrices of the semi-pyramidal fracture surface, Young's modulus and tensile strength of FRP $\left(E_{f}, f_{f u}\right)$, concrete average compressive strength $\left(f_{c}^{\prime}\right)$, thickness and width of the NSM FRP laminate cross section $\left(a_{f}, b_{f}\right)$, and the bond strength and ultimate slip $\left(\tau_{0}, \delta_{1}\right)$ of the constitutive law that simulates the bond between the laminate and the surrounding concrete.

Step 2: Determine the average available resisting bond length and the minimum integer number of FRP strips that cross the CDC (Figure 13a):

$$
\begin{aligned}
& \bar{L}_{R f i}=\frac{h_{w} \cdot \sin \theta \cdot\left(\cot \theta+\cot \theta_{f}\right)}{4 \cdot \sin \left(\theta+\theta_{f}\right)} \\
& N_{f, \text { int }}^{l}=\operatorname{round}\left[h_{w} \cdot \frac{\cot \theta+\cot \theta_{f}}{s_{f}}\right]
\end{aligned}
$$

Step 3: Evaluation of various constants (Figure 13c and 13d):

There are three types of constants:

1) Geometric constants:

Perimeter of CFRP cross section, cross sectional area of the relevant prism surrounding concrete, and CDC length:

$$
L_{p}=2 b_{f}+a_{f} ; A_{c}=s_{f} \frac{b_{w}}{2} ; L_{d}=\frac{h_{w}}{\sin \theta}
$$

2) Mechanical constants:

The laminate tensile strength, concrete tensile strength, and concrete Young's modulus:

$$
\begin{aligned}
& V_{f}^{t r}=a_{f} \cdot b_{f} \cdot f_{f u} \\
& f_{c t m}=1.4\left(\frac{f_{c}^{\prime}-8}{10}\right)^{2 / 3} \\
& E_{c}=2.15 \times 10^{4}\left(\frac{f_{c}^{\prime}}{10}\right)^{1 / 3}
\end{aligned}
$$

3) Bond-Modeling constants: 
Bond modeling constant $\left(J_{1}\right)$, integration constant for the softening friction phase $\left(C_{3}\right)$, constant entering the governing differential equation for elastic phase ( $\lambda$ ), effective resisting bond length $\left(L_{R f e}\right)$, and maximum value of force transferable through bond by the given FRP NSM system $\left(V_{f 1}^{b d}\right)$ :

$$
J_{1}=\frac{L_{p}}{A_{f}}\left[\frac{1}{E_{f}}+\frac{A_{f}}{A_{c} E_{c}}\right] ; C_{3}=\frac{V_{f}^{t r} \cdot J_{1}}{L_{p} \cdot \lambda} ; \frac{1}{\lambda^{2}}=\frac{\delta_{1}}{\tau_{b} J_{1}} ; L_{R f e}=\frac{\pi}{2 \lambda} ; V_{f 1}^{b d}=\frac{L_{p} \lambda \delta_{1}}{J_{1}}
$$

Step 4: Determine the reduction factor of the initial average available resisting bond length ( $\eta$ ), and equivalent value of the average resisting bond length $\left(\bar{L}_{R f i}^{e q}\right)$ :

The average resistance bond length is determined from:

$$
\bar{L}_{R f i}^{e q}=\eta \cdot \bar{L}_{R f i}
$$

where:

$$
\eta=\left\{\begin{array}{l}
\frac{f_{c t m}}{f_{c t m}^{*}} \quad \text { if } f_{c t m}<f_{c t m}^{*} \\
1 \quad \text { if } f_{c t m} \geq f_{c t m}^{*}
\end{array}\right.
$$

with:

$$
f_{c t m}^{*}=\frac{L_{p} \lambda \delta_{1} \sin \left(\lambda \cdot L_{R f i}\right)}{J_{1} \cdot \min \left(L_{R f i} \cdot \tan \alpha, b_{w} / 2\right) \cdot \min \left(s_{f} \cdot \sin \theta_{f}, 2 L_{R f i} \cdot \tan \alpha\right)}
$$

representing the concrete average tensile strength for values larger than which concrete fracture does not occur, where:

$$
L_{R f i}= \begin{cases}\bar{L}_{R f i} & \text { if } \bar{L}_{R f i} \leq L_{R f e} \\ L_{R f e} & \text { if } \bar{L}_{R f i}>L_{R f e}\end{cases}
$$

Step 5: Determine the value of imposed slip in correspondence of which the comprehensive peak force transmissible by $\bar{L}_{R f t}^{e q}$ is attained $\left(V_{f i}\left(\bar{L}_{R f i}^{e q} ; \delta_{L i}\right)\right)$ :

$$
\delta_{L u}=\left\{\begin{array}{lll}
\delta_{L 1}\left(\bar{L}_{R f i}^{e q}\right) & \text { if } & V_{f 1}^{d b}<V_{f}^{t r} \\
\min \left[\delta_{L 1}\left(\bar{L}_{R f i}^{e q}\right) ; \delta_{L i}\left(V_{f}^{t r}\right)\right] & \text { if } & V_{f 1}^{d b} \geq V_{f}^{t r}
\end{array}\right.
$$

where $\delta_{L 1}\left(\bar{L}_{R f i}^{e q}\right)$ is the value of imposed end slip that corresponds with the peak value obtained from the bond-based constitutive law $V_{f i}^{b d}\left(\bar{L}_{R f i}^{e q} ; \delta_{L i}\right)$ : 


$$
\delta_{L 1}\left(\bar{L}_{R f i}^{e q}\right)=\left\{\begin{array}{lll}
\delta_{1}\left[1-\cos \left(\lambda \bar{L}_{R f i}^{e q}\right)\right] & \text { if } & \bar{L}_{R f i}^{e q} \leq L_{R f e} \\
\delta_{1} & \text { if } & \bar{L}_{R f i}^{e q}>L_{R f e}
\end{array}\right.
$$

and $\delta_{L i}\left(V_{f}^{t r}\right)$ is the imposed end slip that corresponds with the strip tensile strength $\left(V_{f}^{t r}=a_{f} \cdot b_{f} \cdot f_{f u}\right)$ :

$$
\delta_{L i}\left(V_{f}^{t r}\right)=\delta_{1}\left\{1-\cos \left[-\arcsin \frac{C_{3}}{\delta_{1}}\right]\right\}
$$

Step 6: Determine the maximum effective shear capacity $V_{f i, \text { eff }}^{\max }$ of the NSM FRP laminate with equivalent average resisting bond length $\bar{L}_{R f}^{e q}$ :

The $V_{f i, e f f}^{\max }$ is evaluated by neglecting the post-peak behavior of the constitutive law:

$$
V_{f i, e f f}^{\max }=\frac{\delta_{1} A_{2}}{2 L_{d} A_{3} \gamma_{\max }}\left[\frac{\pi}{2}-\arcsin \psi-\psi \sqrt{1-\psi^{2}}\right]
$$

where:

$$
A_{2}=\frac{L_{p} \lambda}{J_{1}} ; A_{3}=\frac{\sin \left(\theta_{f}+\theta\right)}{2 \delta_{1}} ; \gamma_{\max }=\frac{2 \delta_{L u}}{L_{d} \sin \left(\theta_{f}+\theta\right)} ; \psi=1-A_{3} \cdot \gamma_{\max } \cdot L_{d}
$$

Step 7: Determine the shear strength contribution provided by a system of NSM FRP laminates:

$$
V_{f d}=2 \cdot N_{f, \text { int }}^{l} \cdot V_{f i, e f f}^{\max } \cdot \sin \theta_{f}
$$

\section{New Approach to Predict Shear Capacity of Reinforced Concrete Beams Strengthened with NSM Technique}

To predict the enhanced shear capacity of RC beams strengthened with NSM FRP laminates, a new shear design approach was developed based on SMCFT and adapted to NSM technique. Adapting the SMCFT to the NSM technique is performed by adding the formulation of NSM technique, suggested by Bianco et al. [10], to the simplified MCFT (BSMCFT), leading to [16]:

$$
v=v_{c}+v_{s}+v_{f}=\beta \sqrt{f_{c}^{\prime}}+\rho_{y} f_{\text {yield }} \cot \theta+2 \cdot N_{f, \text { int }}^{l} \cdot V_{f i, e f f}^{\max } \cdot \frac{\sin \theta_{f}}{b_{w} d}
$$

where the expressions for $\beta$ and $\theta$ are provided by Eq. (2) and (3), respectively, while the longitudinal strain is calculated by Eq. (4). In Eq. (22) $d$ and $b_{w}$ are effective depth and width of the beam, respectively. The experimental results of 80 beams strengthened with different configurations and shear strengthening ratio of FRP reinforcements were used to appraise the predictive performance of the developed approach. By evaluating the ratio between the 
experimental results and the analytical predictions, an average value 1.12 was obtained for the developed approach with a COV of $8.9 \%$ (Table 5). More information about the beams and results of this approach can be found in [1, 3 , $4,9,16,30-34]$.

\section{Proposed Approach for Predicting the Shear Capacity of RC Beams Strengthened with Hybrid Composite Plate}

In a rectangular non-cracked section the maximum shear stress in the cross section can be determined by Eq. (23) [3536]:

$$
\tau_{\max }=\frac{V Q}{I t}=\frac{3 V}{2 A}
$$

where $V$ is the total shear force, $Q$ and $I$ are the first and second moment of area, respectively, and $t$ is the thickness of the cross section of area A. Shear resistance of the SHCC plate by assuming perfect bond between SHCC plate and concrete substrate can be expressed as:

$$
V_{S H C C}=2\left(2 / 3 t_{S H C C} h_{S H C C} \tau_{\text {avg }}\right)
$$

where $\tau_{\text {avg }}$ is the average shear stress of the SHCC according to the results presented in [37] is assumed 3.5 MPa. Note that the factor 2 originates from that the SHCC plates are applied on both sides of the beam [16]. The shear strength of a RC beam strengthened with HCP can be determined by following Eq. (24):

$$
v=v_{c}+v_{s}+v_{f}+v_{S H C C}=\beta \sqrt{f_{c}^{\prime}}+\rho_{y} f_{\text {yield }} \cot \theta+2 . N_{f, \text { int }}^{l} \cdot V_{f, \text { eff }}^{\max } \cdot \frac{\sin \theta_{f}}{\left(2 \times b_{w}^{*}\right) d}+\frac{4 t_{S H C C} h_{S H C C} \tau_{\text {avg }}}{3\left(2 \times b_{w}^{*}\right) d}
$$

where $b_{w}^{*}$ is the width of the base of the concrete semi-pyramidal tensile fracture. More information about this parameter is presented in next section. The solution procedure to calculate the shear strength of the concrete beams, according to the BSMCFT adapted to HCP technique, is obtained applying the following procedures (Figure 14):

Step 1: Input parameters;

Step 2: Assume a value for $\varepsilon_{x}$;

Step 3: Calculate the crack spacing using Eq. (5);

Step 4: Calculate $\beta$ and $\theta$ using Eq. (2) and Eq. (3), respectively.

Step 5: Calculate the shear strength based on Eq. (25). 
Step 6: Calculate the longitudinal strain, $\varepsilon_{x}$, according to Eq. (4) and compare to $\varepsilon_{x}$ of step 1. Return to Step 2

with $\varepsilon_{x}$ that has been calculated in Step 5 until $\left|\varepsilon_{x}^{q+1}-\varepsilon_{x}^{q}\right| / \varepsilon_{y}$ yield $\leq 10^{-6}$.

\section{Assessment of the predictive performance of the considered formulations}

In the RC beams strengthened with NSM CFRP laminates (R-NSM-4L90 and T-NSM-4L45), the width of the base of the concrete semi-pyramidal tensile fracture $\left(b_{w}^{*}\right)$ is limited to half of the width of the beams' cross section ( $\left.b_{w}^{*}=b_{w} / 2\right)$. In the beams strengthened with HCPs with no anchors, the failure mode featured a detachment of the HCPs together with a concrete cover from the rest of the beam. The thickness of the concrete cover that was attached to the HCPs varied from $5 \mathrm{~mm}$ to $10 \mathrm{~mm}$. As a result, for these cases the contribution of the HCPs to the shear resistance of the beams should be based on a $b_{w}^{*}$ that varies from $b_{w}^{*}=t_{\text {SHCC }}+5 \mathrm{~mm}$ to $b_{w}^{*}=t_{\text {SHCC }}+10 \mathrm{~mm}$, where the thickness of the SHCC plate $\left(t_{S H C C}\right)$ is $20 \mathrm{~mm}$. In this study an average value of $b_{w}^{*}=27.5 \mathrm{~mm}$ was considered for the beams shear strengthened with HCPs and bonded with epoxy adhesive only. For the beams strengthened with HCP with mechanical anchors, the width of the base of the concrete semi-pyramidal tensile fracture was taken equal to $b_{w}^{*}=\left(b_{w}+2 \mathrm{t}_{H C P}\right) / 2$.

Eq. (10c) provided in CEB-FIP Model Code [25] for conventional concretes, was used in the present formulation because parametric studies have demonstrated that the Young's modulus has a small influence on the shear contribution of CFRP laminates [28].

Since in the beams shear strengthened with HCPs the failure occurred in the concrete substrate, the following values were adopted based on the recommendations of Bianco et al. [28-29]:, $\alpha=28.5^{\circ}, \tau_{0}=20.1 \mathrm{MPa}$, and $\delta_{1}=7.12 \mathrm{~mm}$. The maximum aggregate size $\left(a_{g}\right)$ was $25 \mathrm{~mm}$ in all beams. Since the R-7S-R beam failed in flexural bending, this beam is not included in the evaluation of the proposed model. In the T-5L45-BC and T-D-5L45-BC beams it is assumed that the connectors behave similar to steel stirrups. Accordingly, an equivalent horizontal distance $(s=300$ $\mathrm{mm}$ ) is assumed for these two beams (Figure 15).

Table 6 summarizes all the results related to the tested beams. The ratio between the experimental results and the analytical predictions in terms of shear capacity is 1.04 and the coefficient of variation is $10 \%$. The results in this table 
show the capability of BSMCFT approach to predict with good accuracy the ultimate shear capacity of RC beams strengthened or repaired with HCPs.

\section{Conclusion}

The effectiveness of Hybrid Composite Plates (HCPs) for the shear strengthening of reinforced concrete (RC) beams was investigated by carrying out an extensive experimental program which included seven rectangular and ten T cross section beams. Based on the obtained results, the following conclusions are drawn:

- HCPs is an effective technique to increase the shear capacity of RC beams.

- The maximum load carrying capacity of strengthened beams with HCPs was $105 \%$ and $157 \%$ higher than the corresponding rectangular and $\mathrm{T}$ cross-section beams, respectively, without any shear reinforcement (control beams).

- The strengthening technique that consisted of HCPs with CFRP laminates at a $45^{\circ}$ angle was more effective in terms of maximum load carrying capacity compared to $90^{\circ}$.

- The effectiveness level of the HCP technique was limited by the tensile strength of the concrete substrate of the RC beams, having the maximum tensile strain in the CFRP laminates not exceed $25 \%$ of its ultimate strain. Therefore mechanical anchors were used to prevent this premature detachment.

- The load carrying capacity of the T cross-section beams strengthened with HCP technique was limited by the shear strengthening discontinuity at the web-flange intersection. In these beams the failure crack propagated through this zone.

- The obtained results demonstrated the efficiency of HCPs for the shear repairing of damaged RC beams. The load carrying capacity of the damaged beams strengthened with HCPs technique was $96 \%$ of the capacity of undamaged beams strengthened with identical HCPs.

An analytical model was proposed to estimate the shear capacity of reinforced concrete beams strengthened with HCPs based on the SMCFT and Bianco et al. formulations. The estimated shear capacities based on the proposed model were compared with those obtained in the tested beams. An average value of 1.04 for the ratio between the experimental results and the analytical predictions was obtained with a coefficient of variation of $10 \%$. This suggests that the proposed analytical model can lead to rather accurate results. 


\section{Acknowledgment}

The study reported in this paper is part of the project "PrePam -Pre-fabricated thin panels using advanced materials for structural rehabilitation", with the reference PTDC/ECM/114511/2009. The first author acknowledges the grant provided by this project.
$A_{f} \quad$ Area of the strip's cross section
$A_{s x} \quad$ Area of longitudinal steel reinforcement
$A_{2} \quad$ Integration constant entering the expressions to evaluate the $V_{f i, e f f}^{\max }$
$A_{3} \quad$ Integration constant entering the expressions to evaluate the $V_{f i, e f f}^{\max }$
$C_{3} \quad$ Integration constant for the softening friction phase
$E_{c} \quad$ Modulus of elasticity for concrete
$E_{f} \quad$ Modulus of elasticity of FRP
$J_{1} \quad$ Bond modeling constant
$L_{d} \quad$ CDC length
$L_{p} \quad$ Effective perimeter of the strip cross section
$L_{R f e} \quad$ Effective resisting bond length
$L_{R f i} \quad i^{\text {th }}$ strip resisting bond length
$\bar{L}_{R f i}^{e q} \quad$ Equivalent average resisting bond length
$\bar{L}_{R f i} \quad$ Average available resisting bond length
$N_{f, \text { int }}^{l} \quad$ Equivalent average resisting bond length
$V \quad$ Shear force
$V_{a} \quad$ Internal friction
$V_{c} \quad$ Shear force in Concrete
$V_{d} \quad$ Dowel force in longitudinal bars
$V_{f} \quad$ Shear resistance contribution of fibers
$V_{f}^{t r} \quad$ Strip tensile rupture capacity
$V_{f d} \quad$ Design value of the NSM shear strengthening contribution
$V_{f i, e f f}^{\max } \quad$ Maximum effective capacity
$V_{f 1}^{b d} \quad$ Maximum value of force transferable through bond by the given FRP NSM system
$V_{s} \quad$ Shear resistance contribution of steel reinforcement
$a_{f} \quad$ Width of FRP laminate
$a_{g} \quad$ Aggregate size
$b_{f} \quad$ Thickness of FRP laminate
$b_{w} \quad$ Width of strengthened cross section
$d \quad$ Effective depth
$f_{c}^{\prime} \quad$ Cylinder compressive strength of concrete
$f_{\text {SHCC }} \quad$ Tensile strength of SHCC
$f_{c t m}^{*} \quad$ Value of concrete average tensile strength for values larger than which concrete fracture does not occur

\section{Notation}




$\begin{array}{ll}f_{c t m} & \text { Concrete average tensile strength } \\ f_{f u} & \text { Ultimate tensile strength of FRP. } \\ f_{y \text { yeild }} & \text { Yield stress in transverse steel reinforcement } \\ h_{S H C C} & \text { Height of SHCC } \\ h_{w} & \text { Height of web of beam } \\ s_{f} & \text { Spacing of NSM shear reinforcement } \\ s_{x e} & \text { Effective longitudinal crack spacing } \\ t_{S H C C} & \text { Thickness of SHCC plate } \\ v & \text { Shear stress } \\ v_{c} & \text { Shear stress in concrete } \\ v_{s} & \text { Shear stress in transverse reinforcement } \\ v_{S H C C} & \text { Shear stress in SHCC plate } \\ \alpha & \text { Angle defining the concrete fracture surface } \\ \beta & \text { Factor accounting for the tensile stress in the cracked concrete } \\ \delta_{1} & \text { Slip corresponding to the end of softening friction } \\ \delta_{L i} & \text { Imposed slip at the loaded extremity of the } i^{t h} \text { strip } \\ \delta_{L u} & \text { Imposed slip in correspondence of which the comprehensive peak force transmissible by } \bar{L}_{R f i}^{e q} \text { is } \\ \delta_{L 1} & \text { attained } \\ \varepsilon_{x} & \text { Value of } \delta_{L i} \text { defining the end of the first phase of the bond-based constitutive law } \\ \varepsilon_{y y e i l d} & \text { Longitudinal strain } \\ \gamma_{\text {max }} & \text { Yield strain in transverse steel reinforcement } \\ \gamma_{x y} & \text { CDC opening angle for which the maximum effective capacity is attained } \\ \eta & \text { Shear strain } \\ \lambda & \text { Reduction factor of the initial average available resisting bond length } \\ \theta & \text { Constant entering the governing differential equation for elastic phase } \\ \theta_{f} & \text { Direction of the principal stress/strain } \\ \rho_{s x} & \text { Inclination of FRP laminates } \\ \rho_{f} & \text { Longitudinal steel reinforcement ratio } \\ \tau_{0} & \text { FRP ratio } \\ \psi & \text { Constant necessary to evaluate the maximum effective capacity provided by the equivalent } \\ & \text { average resisting bond length } \\ & \end{array}$

\section{References}

1. Rizzo, A.; and De Lorenzis, L.; "Behaviour and capacity of RC beams strengthened in shear with NSM FRP reinforcement." Construction and Building Materials, 3(4), 2009: pp. 1555-1567.

2. $\quad$ Khalifa, A.; Nanni, A.; "Improving shear capacity of existing RC T-section beams using CFRP composites." Cement \& concrete Composites, 2000. 22 (3): p. 165-174.

3. De Lorenzis, L.; Nanni, A.; "Shear Strengthening of Reinforced Concrete Beams with Near-Surface Mounted Fiber-Reinforced Polymer Rods." ACI Structural Journal, 2001. 98(1): p. 60-68. 
4. Chaallal, O.; Mofidi, A.; Benmokrane, B.; Neale, K.; "Embedded Through-Section FRP Rod Method for Shear Strengthening of RC Beams: Performance and Comparison with Existing Techniques." Composites for Construction, 2011. 15(3): p. 374-383.

5. Khalifa, A.; Tumialan, G.; Nanni, A.; Belarbi, A.; "Shear Strengthening of Continuous RC Beams Using Externally Bonded CFRP Sheets." in 4th International Symposium on FRP for Reinforcement of Concrete Structures (FRPRCS4)1999: Baltimore. p. 995-1008.

6. Barros, J.A.O.; Dias, S.J.E.; "Shear strengthening of reinforced concrete beams with laminate strips of CFRP." in International Conference Composites in Constructions (CCC2003),2003: Cosenza.

7. Mofidi, A.; Chaallal, O.; "Shear Strengthening of RC Beams with EB FRP: Influencing Factors and Conceptual Debonding Model." Journal of Composites for Construction, 2011. 15: p. 62-74.

8. Alzoubi, F.; Qi, Z.; Zheng-ling, L.; "Shear strengthening of pre-damaged reinforced concrete beams with carbon fiber reinforced polymer sheet strips." Journal of Chongqing University: English Edition, 2007. 6(4): p. 305-310.

9. Dias, S.J.E.; Barros, J.A.O.; "Performance of reinforced concrete T beams strengthened in shear with NSM CFRP laminates." Engineering Structures, 2010. 32(2): p. 373-384.

10. Bianco, V.; Barros, J.A.O.; Monti, G.; Three dimensional mechanical model for simulating the NSM FRP strips shear strength contribution to RC beams." Engineering Structures, 2009. 31(4): p. 815-826.

11. Sena-Cruz, J.; Barros, J.A.O.; Coelho, M.; Silva, L.; "Efficiency of different techniques in flexural strengthening of RC beams under monotonic and fatigue loading." Construction and Building Materials, 2012. 29: p. 175-182.

12. Napoli, A. M.F.; Martinelli, E.; Nanni, A.; Realfonzo, R.; "Modelling and Verification of Response of RC Slabs Strengthened in Flexure with Mechanically Fastened FRP Laminates." Magazine of Concrete Research, 2012, 62(8), p. 593-605.

13. Coelho, M.; Fernandes, P.; Sena-Cruz, J.M.; Barros, J.A.O.; "Bond behavior between concrete and multidirectional CFRP laminates using the MF-EBR strengthening technique." Advanced Materials Research, 2012. 452: p. 1110-1115.

14. Baghi, H.; Barros, J.A.O.; Ventura-Gouveia, A.; "Shear Strengthening of Reinforced Concrete Beams with Hybrid Composite Plates." Advances in Structural Engineering, 2016, DOI: 10.1177/1369433215622873.

15. Esmaeeli, E.; Barros, J.A.O.; "Flexural strengthening of RC beams using hybrid composite plate (HCP): experimental and analytical study." Composites Part B Journal, 79, 604-620, 2015.

16. Baghi, H.; "The effectiveness of SHCC-FRP panels of the shear resistance of RC beams." 2015, University of Minho, PhD Thesis.

17. Shang, Q.; Zijl, G.V.; "Characterizing the Shear Behaviour of Strain-Hardening Fiber-Reinforced CementBased Composites." Journal of the South African Institution of Civil Engineering, 2007. 49(2): p. 16-23.

18. Chalioris, C.E. "Steel fibrous RC beams subjected to cyclic deformations under predominant shear." Engineering Structure, 2013. 49: p. 104-118.

19. Mechtcherine, V.; Millon, O.; Butler, M.; Thoma, K.; "Mechanical Behavior of SHCC under Impact Loading." in High Performance Fiber Reinforced Cement Composites 6, 2012, RILEM. p. 297-304.

20. J. Vecchio, F.; P. Collins, M.; "The Modified Compression-Field Theory for Reinforced Concrete Elements Subjected to Shear" ACI Journal Proceedings, 1986: p. 219-231. 
21. de Normalisation, C. E.; "Concrete - Part 1: Specification, performance, production and conformity." EN2061, CEN., 2000, 69.

22. ISO, E.; "Metallic materials Tensile testing-Part 1: Method of test (at ambient temperature)." Brussels: European committee for standardization (cen), 2000.

23. European Standard, "Plastics - Determination of tensile properties Part 5: Test conditions for unidirectional fibre-reinforced plastic composites." ISO 527-5, Geneva (Switzerland), International Organization for Standardization (ISO), 1997.

24. Esmaeeli, E.; Barros, J.; and Mastali, M; " Effects of curing conditions on crack bridging response of PVA reinforced cementitious matrix." 8th RILEM international symposium on fibre reinforced concrete: challenges and opportunities (BEFIB 2012) Guimaraes, Portugal.

25. du Béton, C.E.I., "CEB-FIP model code 2010, first completed draft," 2010, Comité Euro-International du Béton, Lausanne, Switzerland.

26. Sang-Yeol, P.; "Prediction of Shear Strength of R/C beams using Modified Compression Field Theory and ACI Code." KCI Concrete Journal, 1999. 11(3): p. 5-17.

27. Bentz, E.C.; Vecchio, F.J.; Collins, M.P.; "Simplified Modified Compression Field Theory for Calculating Shear Strength of Reinforced Concrete Elements." ACI Structural Journal, 2006. 103(4): p. 614-624.

28. Bianco, V.; Monti, G.; Barros, J.A.O.; "Design formula to evaluate the NSM FRP strips shear strength contribution to a RC beam." Composites Part B: Engineering, 2014. 56: p. 960-971.

29. Bianco, V.; Barros, J.A.O.; Monti, G.; "Three dimensional mechanical model to simulate the NSM FRP strips shear strength contribution to a RC beam: parametric studies." Engineering Structures, 2012. 37: p. 50-62.

30. Dias, S.J.E.; Barros, J.A.O.; "Shear strengthening of RC beams with NSM CFRP laminates: Experimental research and analytical formulation." Composite Structures, 99, 2013: pp. 477-490.

31. Dias, S.J.E.; Barros, J.A.O.; "Shear strengthening of RC T-section beams with low concrete using NSM CFRP laminates." Journal Cement \& Concrete Composites, 2011. 3(2): pp. 334-345.

32. Dias, S.J.E.; Barros, J.A.O.; "Shear Strengthening of T Cross Section Reinforced Concrete Beams by Near Surface Mounted Technique." ASCE Journal of Composites for Construction, 12(3), 2008: pp. 300-311.

33. Dias, S.J.E.; "Experimental and anlytical research in the shear strengthening of reinforced concreet beams using the near surface mounted technique with CFRP strips," in Department of Civil Engineering 2008, University of Minho, Guimarães-Portugal, in Portugese.

34. Islam, A.A.; "Effective methods of using CFRP bars in shear strengthening of concrete girders." Engineering Structures, 31(3), 2009: pp. 709-714.

35. Blanksvärd, T.; "Strengthening of concrete structures by the use of mineral based composites," 2007, Luleå University of Technology, Master Thesis.

36. Blanksvärd, T.; "Strengthening of concrete structures by the use of mineral based composites," 2009, Luleå University of Technology, PhD Thesis.

37. Baghi, H., Barros, J. A. O., 2016 "Shear Properties of the Strain Hardening Cementitious Composite Material", Journal of Materials in Civil Engineering (ASCE), DOI: 10.1061/(ASCE)MT.19435533.0001603. 


\section{LIST OF TABLE CAPTIONS}

Table 1- Shear strengthening/reinforcement in the monitored shear span of the tested beams

Table 2 - Material Properties

Table 3- Reinforcing properties

Table 4 - Results in terms of load, deflection, and failure mode

Table 5: Summary of experimental and analytical results [16]

Table 6: Analytical vs. experimental results of the strengthened and repaired beams with HCPs 
Table 1-Shear strengthening/reinforcement in the monitored shear span of the tested beams

\begin{tabular}{|c|c|c|c|c|c|c|}
\hline Series & $\begin{array}{c}\text { Beam } \\
\text { designation }\end{array}$ & $\begin{array}{c}\text { Shear } \\
\text { strengthening/reinforcement } \\
\text { configuration }\end{array}$ & Quantity & $\begin{array}{c}\text { Connection } \\
\text { of the } \\
\text { HCP/SHCC } \\
\text { to } \\
\text { substrate }\end{array}$ & $\begin{array}{l}\text { connector } \\
\text { of the } \\
\text { web - } \\
\text { flange }\end{array}$ & $\begin{array}{l}\text { Spacing, } \\
\qquad s_{f} \\
(\mathrm{~mm})\end{array}$ \\
\hline \multirow{7}{*}{$A$} & $R-C-R$ & - & - & - & - & - \\
\hline & $\begin{array}{l}R-N S M- \\
4 L 90\end{array}$ & $\begin{array}{l}\text { NSM CFRP laminates of } \\
1.4 \times 10 \mathrm{~mm}^{2} \text { cross section }\end{array}$ & $\begin{array}{l}2 \times 4 \text { CFRP } \\
\text { laminates }\end{array}$ & - & - & 180 \\
\hline & $R-S P$ & SHCC Plates & $\begin{array}{l}20 \mathrm{~mm} \\
\text { thickness } \\
\text { of SHCC }\end{array}$ & \multirow{3}{*}{ Adhesive } & - & - \\
\hline & $R-4 L 90$ & \multirow{3}{*}{$\begin{array}{l}\text { HCPs ( } 20 \mathrm{~mm} \text { thickness of } \\
\text { SHCC reinforced with CFRP } \\
\text { laminates of } 1.4 \times 10 \mathrm{~mm}^{2} \\
\text { cross section) }\end{array}$} & $\begin{array}{l}2 \times 4 \text { CFRP } \\
\text { laminates }\end{array}$ & & \multirow{3}{*}{-} & 180 \\
\hline & $R-3 L 45$ & & \multirow[b]{2}{*}{$\begin{array}{l}2 \times 3 \text { CFRP } \\
\text { laminates }\end{array}$} & & & 250 \\
\hline & $R-D-3 L 45-B$ & & & $\begin{array}{l}\text { Adhesive \& } \\
\text { mechanical } \\
\text { anchors }\end{array}$ & & 150 \\
\hline & $R-7 S-R$ & Steel stirrups & $\phi 8$ & & - & 100 \\
\hline \multirow{9}{*}{$B$} & $T-C-R$ & - & - & - & - & - \\
\hline & $\begin{array}{l}T-N S M- \\
3 L 45\end{array}$ & $\begin{array}{l}\text { NSM CFRP laminates of } \\
1.4 \times 10 \mathrm{~mm}^{2} \text { cross section }\end{array}$ & $\begin{array}{l}2 \times 4 \text { CFRP } \\
\text { laminates }\end{array}$ & - & - & 275 \\
\hline & $T-S P$ & SHCC Plates & $\begin{array}{l}20 \mathrm{~mm} \\
\text { thickness } \\
\text { of SHCC }\end{array}$ & - & - & - \\
\hline & $T-3 L 45$ & \multirow{6}{*}{$\begin{array}{l}\text { HCPs (20 mm thickness of } \\
\text { SHCC reinforced with CFRP } \\
\text { laminates of } 1.4 \times 10 \mathrm{~mm}^{2} \\
\text { cross section) }\end{array}$} & \multirow[b]{2}{*}{$\begin{array}{l}2 \times 3 \text { CFRP } \\
\text { laminates }\end{array}$} & Adhesive & - & \multirow[b]{2}{*}{275} \\
\hline & $T-3 L 45-B$ & & & $\begin{array}{l}\text { Adhesive \& } \\
\text { bolt }\end{array}$ & - & \\
\hline & $T-5 L 45$ & & \multirow{4}{*}{$\begin{array}{l}2 \times 5 \text { CFRP } \\
\text { laminates }\end{array}$} & \multirow{4}{*}{$\begin{array}{l}\text { Adhesive } \& \\
\text { bolt }\end{array}$} & & \multirow{4}{*}{157} \\
\hline & $T-5 L 45-B$ & & & & - & \\
\hline & $T-5 L 45-B C$ & & & & 4 steel & \\
\hline & $\begin{array}{c}T-D-5 L 45- \\
B C\end{array}$ & & & & bars $\phi 10$ & \\
\hline
\end{tabular}


Table 2 -Material Properties

\begin{tabular}{cccc}
\hline Property & Concrete & $\begin{array}{c}\text { CFRP } \\
\text { laminate }\end{array}$ & SHCC \\
\hline $\begin{array}{c}\text { Compressive strength } \\
(\mathrm{MPa})\end{array}$ & 33.0 & - & 32.0 \\
\hline $\begin{array}{c}\text { Tensile strength (MPa) } \\
\text { Elasticity modulus (GPa) }\end{array}$ & - & 2620 & - \\
\hline Maximum strain (\%) & - & 150 & 18 \\
\hline $\begin{array}{c}\text { Tensile stress at crack } \\
\text { initiation (MPa) }\end{array}$ & - & 1.6 & - \\
\hline Tensile strength (MPa) & - & - & 2.7 \\
\hline $\begin{array}{c}\text { Tensile strain at tensile } \\
\text { strength (\%) }\end{array}$ & - & - & 1.3 \\
\hline
\end{tabular}


Table 3-Reinforcing properties

\begin{tabular}{|c|c|c|c|c|c|c|c|}
\hline Property & $\phi 6$ & $\phi 8$ & $\begin{array}{c}\phi \\
10\end{array}$ & $\begin{array}{c}\phi \\
12\end{array}$ & $\begin{array}{c}\phi \\
16\end{array}$ & $\begin{array}{c}\phi \\
20\end{array}$ & $\phi 32$ \\
\hline$f_{\text {sym }}(\mathrm{MPa})$ & 500 & 545 & 530 & 490 & 470 & 575 & 625 \\
\hline$f_{\text {sum }}(\mathrm{MPa})$ & 595 & 610 & 625 & 590 & 565 & 640 & 905 \\
\hline
\end{tabular}


Table 4 - Results in terms of load, deflection, and failure mode

\begin{tabular}{|c|c|c|c|c|c|c|}
\hline Series & $\begin{array}{c}\text { Beam } \\
\text { designation }\end{array}$ & $\begin{array}{l}F_{\max } \\
(k N)\end{array}$ & $\begin{array}{l}\text { Deflection } \\
\text { at loaded } \\
\text { section } \\
(\mathrm{mm})\end{array}$ & $\begin{array}{c}\left(\Delta F / F^{N S M}\right)_{\max } \\
(\%)\end{array}$ & $\frac{F_{\max }}{F_{\max }^{7 S-R}}(\%)$ & Failure mode \\
\hline \multirow{7}{*}{$A$} & $R-C-R$ & 81 & 3.3 & - & 45 & \multirow{3}{*}{ Shear failure } \\
\hline & $R-N S M-4 L 90$ & 143 & 8.2 & 0 & 79 & \\
\hline & $R-S P$ & 130 & 6.3 & 4 & 71 & \\
\hline & $R-4 L 90$ & 151 & 8.3 & 14 & 83 & $\begin{array}{c}\text { Detachment of } \\
\text { the HCPs and } \\
\text { shear failure }\end{array}$ \\
\hline & $R-3 L 45$ & 166 & 12.5 & 39 & 91 & $\begin{array}{c}\text { Detachment of } \\
\text { the HCPs }\end{array}$ \\
\hline & $R-D-3 L 45-B$ & 161 & 10.1 & 37 & 88 & $\begin{array}{c}\text { Detachment of } \\
\text { the HCPs }\end{array}$ \\
\hline & $R-7 S-R$ & 182 & 19.9 & 37 & 100 & Flexural failure \\
\hline \multirow{8}{*}{$B$} & $T-C-R$ & 214 & 3.0 & - & 40 & $\begin{array}{c}\text { Concrete } \\
\text { spalling at the } \\
\text { support } \\
\text { section }\end{array}$ \\
\hline & T-NSM-3L45 & 290 & 5.9 & 0 & 55 & \multirow{2}{*}{ Shear failure } \\
\hline & $T-S P$ & 255 & 5.0 & 11 & 48 & \\
\hline & $T-3 L 45$ & 367 & 5.5 & 85 & 69 & $\begin{array}{c}\text { Detachment of } \\
\text { the HCPs }\end{array}$ \\
\hline & $T-3 L 45-B$ & 363 & 6.2 & 106 & 68 & Shear failure \\
\hline & $T-5 L 45$ & 306 & 5.1 & 14 & 58 & $\begin{array}{c}\text { Debonding of } \\
\text { the HCPs }\end{array}$ \\
\hline & $T-5 L 45-B$ & 364 & 6.3 & 174 & 67 & $\begin{array}{c}\text { Failure } \\
\text { localized at } \\
\text { Web-flange } \\
\text { zone }\end{array}$ \\
\hline & $T-5 L 45-B C$ & 552 & 9.4 & 348 & 104 & Shear failure \\
\hline
\end{tabular}




\begin{tabular}{cccccc}
\hline$T-D-5 L 45-B C$ & 530 & 7.2 & 260 & 100 & Shear failure \\
\hline$T-7 S-R$ & 530 & 8.4 & 285 & 100 & Shear failure \\
\hline
\end{tabular}


Table 5: Summary of experimental and analytical results [16]

\begin{tabular}{|c|c|c|c|c|c|c|}
\hline \multirow[b]{2}{*}{ Beam Label } & \multirow[b]{2}{*}{$\begin{array}{c}f_{c}^{\prime} \\
(\mathrm{MPa})\end{array}$} & \multicolumn{3}{|c|}{ Reinforcement } & \multirow[b]{2}{*}{$\begin{array}{l}F_{\exp } \\
(\mathrm{kN})\end{array}$} & \multirow[b]{2}{*}{$F_{\text {exp. }} / F_{\text {ana. }}$} \\
\hline & & $\theta_{f}$ & $\frac{\rho_{y} f_{y \text { yield }}}{f_{c}^{\prime}}$ & $\frac{\rho_{f} f_{y f}}{f_{c}^{\prime}}$ & & \\
\hline \multicolumn{7}{|c|}{ Dias and Barros $[9,30]$} \\
\hline$C-R-I$ & 39.7 & - & 0 & 0 & 207 & 1.11 \\
\hline $2 S-R-I$ & 39.7 & - & 0.0143 & 0 & 303.8 & 1.18 \\
\hline $7 S-R-I$ & 39.7 & - & 0.038 & 0 & 467.5 & 1.25 \\
\hline $2 S-4 L V-I$ & 39.7 & $90^{\circ}$ & 0.0143 & 0.056 & 337.4 & 1.09 \\
\hline $2 S-7 L V-I$ & 39.7 & $90^{\circ}$ & 0.0143 & 0.09 & 374.1 & 0.99 \\
\hline $2 S-10 L V-I$ & 39.7 & $90^{\circ}$ & 0.0143 & 0.12 & 397.5 & 1.03 \\
\hline $2 S-4 L I 45-I$ & 39.7 & $45^{\circ}$ & 0.0143 & 0.055 & 392.8 & 1.18 \\
\hline $2 S-7 L 145-I$ & 39.7 & $45^{\circ}$ & 0.0143 & 0.9 & 421.7 & 1.05 \\
\hline $2 S-10 L I 45-I$ & 39.7 & $45^{\circ}$ & 0.0143 & 0.13 & 446.5 & 1.09 \\
\hline $2 S-4 L I 60-I$ & 39.7 & $60^{\circ}$ & 0.0143 & 0.49 & 386.4 & 1.22 \\
\hline $2 S-6 L I 60-I$ & 39.7 & $60^{\circ}$ & 0.0143 & 0.076 & 394.4 & 1.13 \\
\hline $2 S-9 L I 60-I$ & 39.7 & $60^{\circ}$ & 0.0143 & 0.11 & 412.7 & 1.01 \\
\hline $4 S-4 L V-I I$ & 39.7 & $90^{\circ}$ & 0.0237 & 0.055 & 424.5 & 1.19 \\
\hline $4 S-7 L V-I I$ & 39.7 & $90^{\circ}$ & 0.0237 & 0.09 & 427.4 & 1.12 \\
\hline $4 S-4 L I 45-I I$ & 39.7 & $45^{\circ}$ & 0.0237 & 0.055 & 442.5 & 1.17 \\
\hline $4 S-7 L / 45-I I$ & 39.7 & $45^{\circ}$ & 0.0237 & 0.09 & 478.1 & 1.07 \\
\hline $4 S-4 L I 60-I I$ & 39.7 & $60^{\circ}$ & 0.0237 & 0.048 & 443.9 & 1.22 \\
\hline $4 S-6 L I 60-I I$ & 39.7 & $60^{\circ}$ & 0.0237 & 0.076 & 457.6 & 1.16 \\
\hline \multicolumn{7}{|c|}{ Dias and Barros [31] } \\
\hline$C-R-I I I$ & 18.6 & - & 0 & 0 & 147 & 1.08 \\
\hline $2 S-R-I I I$ & 18.6 & - & 0.0304 & 0 & 226.5 & 1.08 \\
\hline $4 S-R-I I I$ & 18.6 & - & 0.0508 & 0 & 303.8 & 1.17 \\
\hline $2 S-7 L V-I I I$ & 18.6 & $90^{\circ}$ & 0.0304 & 0.199 & 273.7 & 1.04 \\
\hline $2 S-4 L I 45-I I I$ & 18.6 & $45^{\circ}$ & 0.0304 & 0.122 & 283 & 1.14 \\
\hline $2 S-7 L I 45-I I I$ & 18.6 & $45^{\circ}$ & 0.0304 & 0.199 & 306.5 & 1.08 \\
\hline $2 S-4 L I 60-I I I$ & 18.6 & $60^{\circ}$ & 0.0304 & 0.107 & 281.6 & 1.17 \\
\hline $2 S-6 L I 60-I I I$ & 18.6 & $60^{\circ}$ & 0.0304 & 0.168 & 297.7 & 1.16 \\
\hline $4 S-7 L V-I I I$ & 18.6 & $90^{\circ}$ & 0.0508 & 0.199 & 315.2 & 1.05 \\
\hline $4 S-4 L I 45-I I I$ & 18.6 & $45^{\circ}$ & 0.0508 & 0.122 & 347.2 & 1.17 \\
\hline $4 S-7 L 145-I I I$ & 18.6 & $45^{\circ}$ & 0.0508 & 0.199 & 356.4 & 1.07 \\
\hline $4 S-4 L I 60-I I I$ & 18.6 & $60^{\circ}$ & 0.0508 & 0.107 & 345.6 & 1.19 \\
\hline $4 S-6 L I 60-I I I$ & 18.6 & $60^{\circ}$ & 0.0508 & 0.168 & 362.3 & 1.19 \\
\hline \multicolumn{7}{|c|}{ Dias and Barros [32] } \\
\hline$C-R-I V$ & 31.1 & - & 0 & 0 & 243 & 1.47 \\
\hline $2 S-R-I V$ & 31.1 & - & 0.0182 & 0 & 315 & 1.35 \\
\hline $6 S-R-I V$ & 31.1 & - & 0.0303 & 0 & 410 & 1.27 \\
\hline
\end{tabular}




\begin{tabular}{|c|c|c|c|c|c|c|}
\hline \multirow[b]{2}{*}{ Beam Label } & \multirow[b]{2}{*}{$\begin{array}{c}f_{c}^{\prime} \\
(\mathrm{MPa})\end{array}$} & \multicolumn{3}{|c|}{ Reinforcement } & \multirow[b]{2}{*}{$\begin{array}{l}F_{\text {exp }} \\
(\mathrm{kN})\end{array}$} & \multirow[b]{2}{*}{$F_{\text {exp. }} / F_{\text {ana }}$} \\
\hline & & $\theta_{f}$ & $\frac{\rho_{y} f_{y \text { yield }}}{f_{c}^{\prime}}$ & $\frac{\rho_{f} f_{y f}}{f_{c}^{\prime}}$ & & \\
\hline $2 S-3 L V-I V$ & 31.1 & $90^{\circ}$ & 0.0182 & 0.057 & 316 & 1.24 \\
\hline $2 S-5 L V-I V$ & 31.1 & $90^{\circ}$ & 0.0182 & 0.095 & 357 & 1.29 \\
\hline $2 S-8 L V-I V$ & 31.1 & $90^{\circ}$ & 0.0182 & 0.152 & 396 & 1.25 \\
\hline $2 S-3 L I 45-I V$ & 31.1 & $45^{\circ}$ & 0.0182 & 0.057 & 328 & 1.11 \\
\hline $2 S-5 L / 45-I V$ & 31.1 & $45^{\circ}$ & 0.0182 & 0.095 & 384 & 1.18 \\
\hline $2 S-8 L I 45-I V$ & 31.1 & $45^{\circ}$ & 0.0182 & 0.152 & 382 & 1.05 \\
\hline $2 S-3 L I 60-I V$ & 31.1 & $60^{\circ}$ & 0.0182 & 0.057 & 374 & 1.45 \\
\hline $2 S-5 L I 60-I V$ & 31.1 & $60^{\circ}$ & 0.0182 & 0.085 & 392 & 1.28 \\
\hline $2 S-7 L I 60-I V$ & 31.1 & $60^{\circ}$ & 0.0182 & 0.123 & 406 & 1.22 \\
\hline \multicolumn{7}{|c|}{ Dias [33] } \\
\hline$C-R-V$ & 59.4 & - & 0 & 0 & 207 & 0.79 \\
\hline $3 S-R-V$ & 59.4 & - & 0.0095 & 0 & 359.9 & 1.05 \\
\hline $3 S-6 L V-V$ & 59.4 & $90^{\circ}$ & 0.0095 & 0.025 & 387 & 0.91 \\
\hline $3 S-10 L V-V$ & 59.4 & $90^{\circ}$ & 0.0095 & 0.041 & 491.7 & 0.91 \\
\hline $3 S-5 L 145-V$ & 59.4 & $45^{\circ}$ & 0.0095 & 0.025 & 492.1 & 1.07 \\
\hline $3 S-9 L 145-V$ & 59.4 & $45^{\circ}$ & 0.0095 & 0.041 & 563.6 & 0.99 \\
\hline $3 S-5 L 160-V$ & 59.4 & $60^{\circ}$ & 0.0095 & 0.022 & 497.9 & 1.14 \\
\hline $3 S-8 L 160-V$ & 59.4 & $60^{\circ}$ & 0.0095 & 0.035 & 584.5 & 1.20 \\
\hline $5 S-R-V I$ & 59.4 & - & 0.0143 & 0 & 409.7 & 1.05 \\
\hline $5 S-5 L I 45-V I$ & 59.4 & $45^{\circ}$ & 0.0143 & 0.025 & 559.5 & 1.12 \\
\hline $5 S-9 L I 45-V I$ & 59.4 & $45^{\circ}$ & 0.0143 & 0.041 & 627.5 & 1.03 \\
\hline $5 S-5 \mathrm{LI} 60-\mathrm{VI}$ & 59.4 & $60^{\circ}$ & 0.0143 & 0.022 & 556.4 & 1.16 \\
\hline $5 S-8 L I 60-V I$ & 59.4 & $60^{\circ}$ & 0.0143 & 0.035 & 654.6 & 1.24 \\
\hline \multicolumn{7}{|c|}{ Chaallal et al. [4] } \\
\hline SO-CON-I & 25 & - & 0 & 0 & 180.6 & 0.99 \\
\hline S1-CON-I & 25 & - & 0.0812 & 0 & 230.4 & 1.07 \\
\hline S3-CON-II & 35 & - & 0.0386 & 0 & 255.3 & 0.98 \\
\hline SO-NSM-I & 25 & $90^{\circ}$ & 0 & 0.54 & 331 & 1.13 \\
\hline S1-NSM-I & 25 & $90^{\circ}$ & 0.0812 & 0.54 & 355.9 & 0.98 \\
\hline S3-NSM-II & 35 & $90^{\circ}$ & 0.0386 & 0.39 & 306.5 & 1.04 \\
\hline \multicolumn{7}{|c|}{ De Lorenzis and Nanni [3] } \\
\hline$B V$ & 31 & - & 0 & 0 & 180.6 & 1.09 \\
\hline B90-7 & 31 & $90^{\circ}$ & 0 & 0.31 & 230.4 & 1.08 \\
\hline B90-5 & 31 & $90^{\circ}$ & 0 & 0.44 & 255.3 & 1.07 \\
\hline B45-7 & 31 & $45^{\circ}$ & 0 & 0.45 & 331 & 1.07 \\
\hline B45-5 & 31 & $45^{\circ}$ & 0 & 0.63 & 355.9 & 1.02 \\
\hline$B S V$ & 31 & - & 0.029 & 0 & 306.5 & 1.12 \\
\hline$B S 90-7 A$ & 31 & $90^{\circ}$ & 0.029 & 0.31 & 413.7 & 1.27 \\
\hline
\end{tabular}




\begin{tabular}{|c|c|c|c|c|c|c|}
\hline \multirow[b]{2}{*}{ Beam Label } & \multirow[b]{2}{*}{$\begin{array}{c}f_{c}^{\prime} \\
(\mathrm{MPa})\end{array}$} & \multicolumn{3}{|c|}{ Reinforcement } & \multirow[b]{2}{*}{$\begin{array}{l}F_{\exp } \\
(\mathrm{kN})\end{array}$} & \multirow[b]{2}{*}{$F_{\text {exp. }} / F_{\text {ana. }}$} \\
\hline & & $\theta_{f}$ & $\frac{\rho_{y} f_{\text {y yield }}}{f_{c}^{\prime}}$ & $\frac{\rho_{f} f_{y f}}{f_{c}^{\prime}}$ & & \\
\hline \multicolumn{7}{|c|}{ Rizzo and De Lorenzis [1] } \\
\hline C & 29.3 & - & 0.0401 & 0 & 244.3 & 1.04 \\
\hline$N R 90-73-b$ & 29.3 & $90^{\circ}$ & 0.0401 & 0.5191 & 297 & 1.04 \\
\hline$N R 90-45-b$ & 29.3 & $90^{\circ}$ & 0.0401 & 0.8421 & 301.5 & 0.99 \\
\hline NR45-146- $a$ & 29.3 & $45^{\circ}$ & 0.0401 & 0.3671 & 322.6 & 1.11 \\
\hline$N R 45-73-a$ & 29.3 & $45^{\circ}$ & 0.0401 & 0.7341 & 300.3 & 0.94 \\
\hline$N L 90-73-a$ & 29.3 & $90^{\circ}$ & 0.0401 & 0.3097 & 345.3 & 1.20 \\
\hline NL45-146- $a$ & 29.3 & $45^{\circ}$ & 0.0401 & 0.219 & 309.7 & 1.06 \\
\hline \multicolumn{7}{|c|}{ Islam [34] } \\
\hline Beam1 & 49.75 & - & 0.0338 & 0 & 365 & 0.86 \\
\hline Beam2 & 49.75 & $90^{\circ}$ & 0.0338 & 0.1404 & 454 & 0.93 \\
\hline Beam3 & 49.75 & $90^{\circ}$ & 0.0169 & 0.1404 & 427 & 1.09 \\
\hline Beam4 & 49.75 & $90^{\circ}$ & 0.0008 & 0.1404 & 436 & 1.28 \\
\hline & & & & & Ave & 1.12 \\
\hline & & & & & COV & $8.9 \%$ \\
\hline
\end{tabular}


Table 6: Analytical vs. experimental results of the strengthened and repaired beams with HCPs

\begin{tabular}{|c|c|c|c|c|c|c|c|c|}
\hline \multirow[b]{2}{*}{ Beam Label } & \multirow{2}{*}{$\begin{array}{c}f_{c}^{\prime} \\
(M P a)\end{array}$} & \multicolumn{4}{|c|}{ Reinforcement } & \multirow{2}{*}{$\begin{array}{l}F_{\text {ana. }} \\
(k N)\end{array}$} & \multirow[b]{2}{*}{$F_{\text {exp. }}(k N)$} & \multirow{2}{*}{$F_{\text {exp. }} / F_{\text {ana }}$} \\
\hline & & $\rho_{s x}$ & $\theta_{f}$ & $\frac{\rho_{y} f_{y \text { yield }}}{f_{c}^{\prime}}$ & $\frac{\rho_{f} f_{f f u}}{f_{c}^{\prime}}$ & & & \\
\hline \multicolumn{9}{|c|}{ Rectangular cross section beams } \\
\hline$R-C-R$ & \multirow{7}{*}{32.7} & \multirow{7}{*}{0.016} & - & \multirow{6}{*}{-} & - & 90 & 81 & 0.90 \\
\hline$R-N S M-4 L 90$ & & & $90^{\circ}$ & & 0.08 & 130 & 143 & 1.10 \\
\hline$R-S P$ & & & - & & - & 133 & 130 & 0.98 \\
\hline$R-4 L 90$ & & & $90^{\circ}$ & & 0.08 & 160 & 151 & 0.94 \\
\hline$R-3 L 45$ & & & $45^{\circ}$ & & 0.08 & 175 & 166 & 0.95 \\
\hline$R-D-3 L 45-B$ & & & $45^{\circ}$ & & 0.14 & 179 & 161 & 0.90 \\
\hline$R-7 S-R$ & & & - & 0.11 & - & - & 182 & - \\
\hline \multicolumn{9}{|c|}{$T$ cross section beams } \\
\hline$T-C-R$ & \multirow{10}{*}{32.7} & \multirow{10}{*}{0.029} & \multirow[b]{2}{*}{ - } & \multirow{9}{*}{-} & - & 186 & 214 & 1.15 \\
\hline T-NSM-3L45 & & & & & - & 251 & 290 & 1.15 \\
\hline$T-S P$ & & & \multirow{7}{*}{$45^{\circ}$} & & 0.064 & 258 & 255 & 0.99 \\
\hline$T-3 L 45$ & & & & & 0.064 & 278 & 367 & 1.32 \\
\hline$T-3 L 45-B$ & & & & & 0.064 & 311 & 363 & 1.17 \\
\hline$T-5 L 45$ & & & & & 0.11 & 307 & 306 & 1.00 \\
\hline$T-5 L 45-B$ & & & & & 0.11 & 370 & 364 & 0.98 \\
\hline$T-5 L 45-B C$ & & & & & 0.11 & 524 & 552 & 1.05 \\
\hline$T-D-5 L 45-B C$ & & & & & 0.11 & 524 & 530 & 1.01 \\
\hline$T-7 S-R$ & & & - & 0.056 & - & 464 & 530 & 1.14 \\
\hline & & & & & & & Average & 1.04 \\
\hline & & & & & & & SD & 0.11 \\
\hline & & & & & & & COV & $10 \%$ \\
\hline
\end{tabular}




\section{LIST OF FIGURE CAPTIONS}

Figure 1: Schematic representation of Hybrid Composite Plates (HCPs) for shear strengthening of reinforced concrete beams

Figure 2: Geometry, reinforcement arrangement, and location of LVDT in rectangular beams; a) R-7S-R beam; b) R-C-R beam (dimensions in $\mathrm{mm}$ )

Figure 3: Geometry, reinforcement arrangement, and location of LVDT in T cross section beams; a) T-7S$\mathrm{R}$ beam; $\mathrm{b}) \mathrm{T}-\mathrm{C}-\mathrm{R}$ beam (dimensions in $\mathrm{mm}$ )

Figure 4: Geometry, shear strengthening details, and layout of strain gages for beams with a rectangular cross-section (dimensions in $\mathrm{mm}$ )

Figure 5: Geometry, shear strengthening details, and layout of strain gages for beams with a T crosssection (dimensions in $\mathrm{mm}$ )

Figure 6 - The envelope and the average tensile stress versus crack opening displacement (COD)obtained in notched specimens [14]

Figure 7: The relation between the applied torque to axial tension force in the fastener

Figure 8: Load vs. deflection at the loaded-section of series of: a) rectangular cross section; b) T cross section beams

Figure 9: $\Delta F / F^{N S M-3 L 45}$ vs. deflection at the loaded-section for the beams strengthened with SHCC/HCPs; a) Rectangular cross section beams; b) T cross section beams

Figure 10: Crack pattern at failure of rectangular cross section beams

Figure 11: Crack pattern at failure of T cross section beams

Figure 12: Force vs. strain in monitored laminates in SGs where the maximum strains were registered a) rectangular cross section beams, b) T cross section beams

Figure 13: Schematic representation of the Bianco et al. [10] model; a) average-available-bond-length NSM strip and concrete prism of influence; b) adopted local bond stress-slip relationship; c) NSM strip confined to the corresponding concrete prism of influence and semi-pyramidal fracture surface; $d$ ) sections of the concrete prism; e) The mode of failure of an NSM FRP laminate subjected to an imposed end slip.

Figure 14: Calculation procedure of BSMCFT adapted to HCP technique

Figure 15: Equivalent distance between steel stirrups $(s)$ in the T-D-5L45-BC and T-5L45-BC beams 

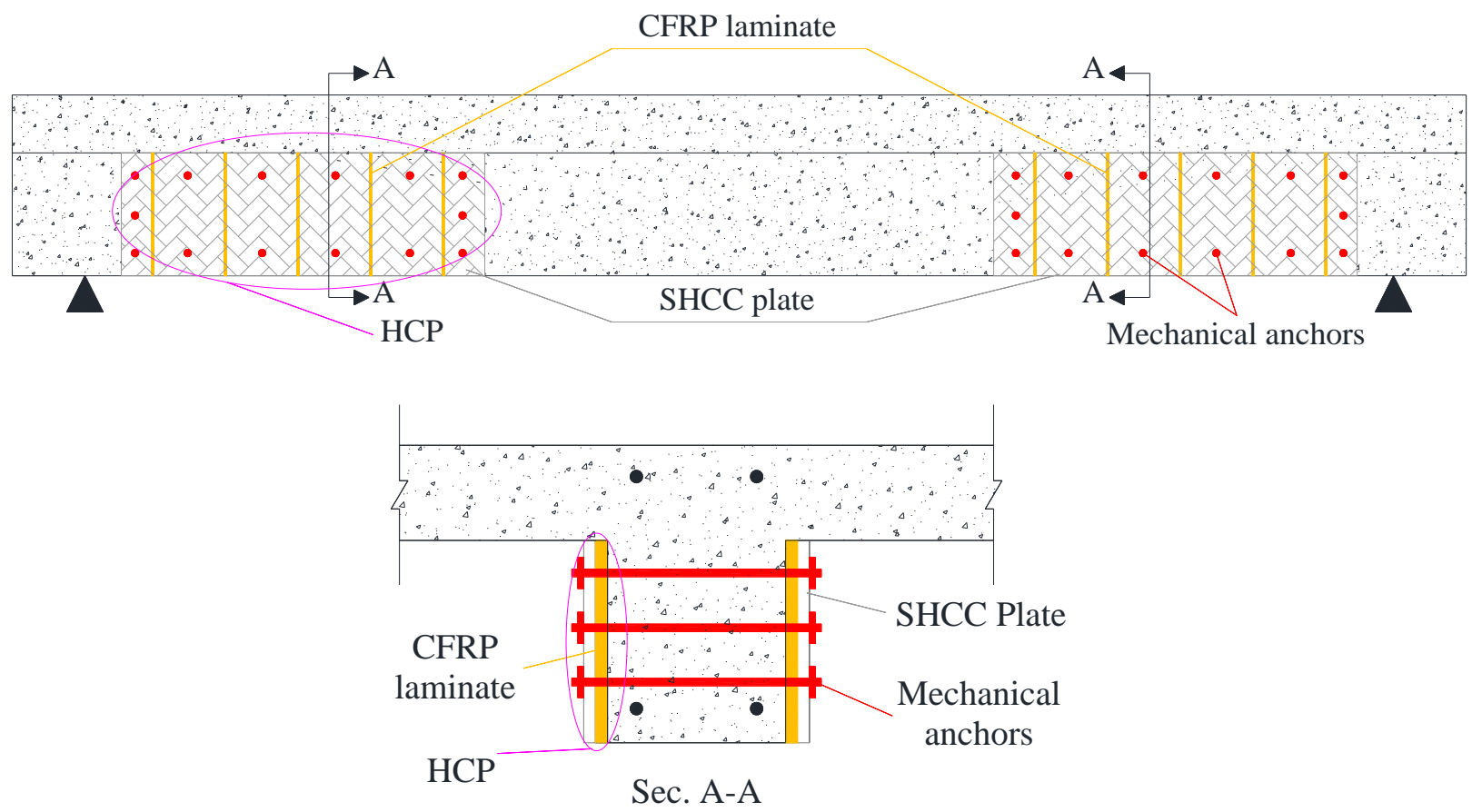

Figure 1: Schematic representation of Hybrid Composite Plates (HCPs) for shear strengthening of reinforced concrete beams 

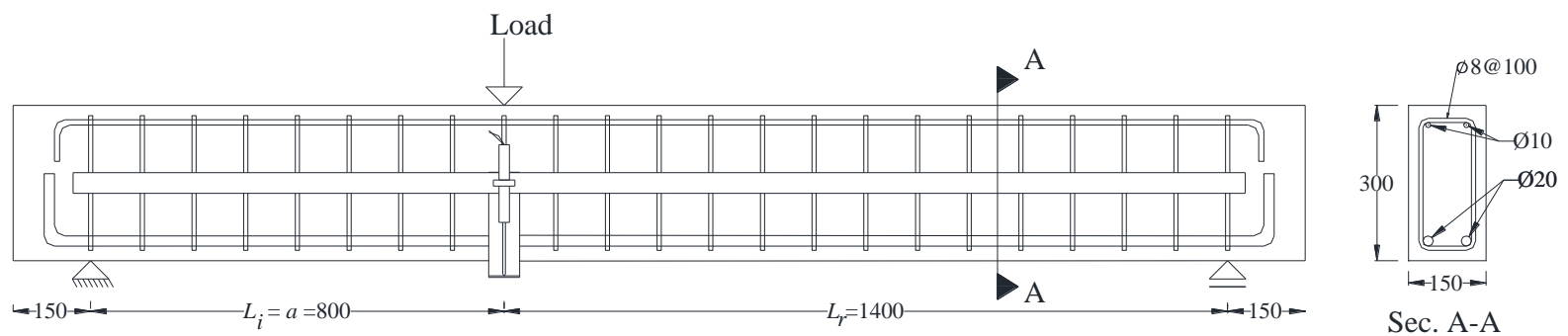

a) R-7S-R
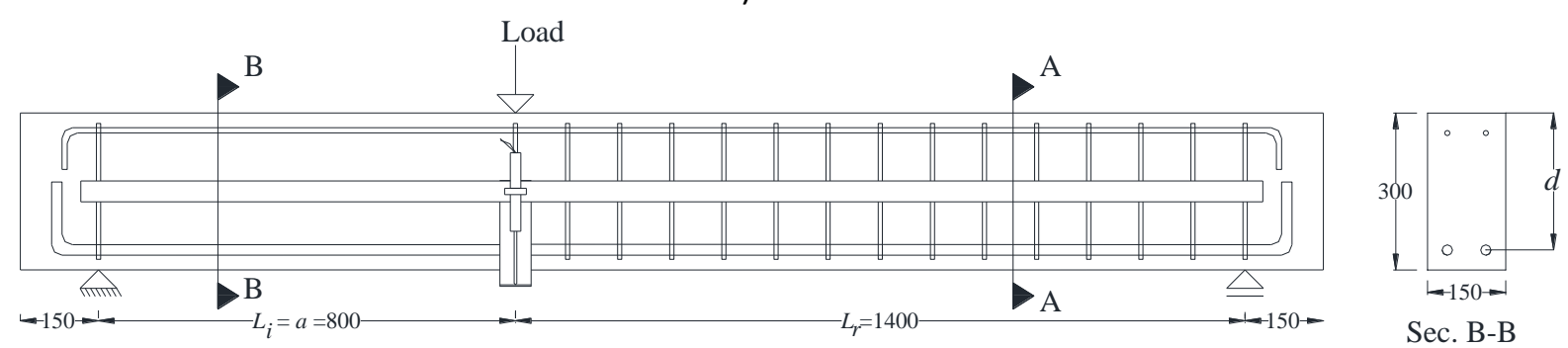

b) R-C-R

Figure 2: Geometry, reinforcement arrangement, and location of LVDT in rectangular beams; a) $R-7 S-R$ beam; $b$ )

$R-C-R$ beam (dimensions in $\mathrm{mm}$ ) 

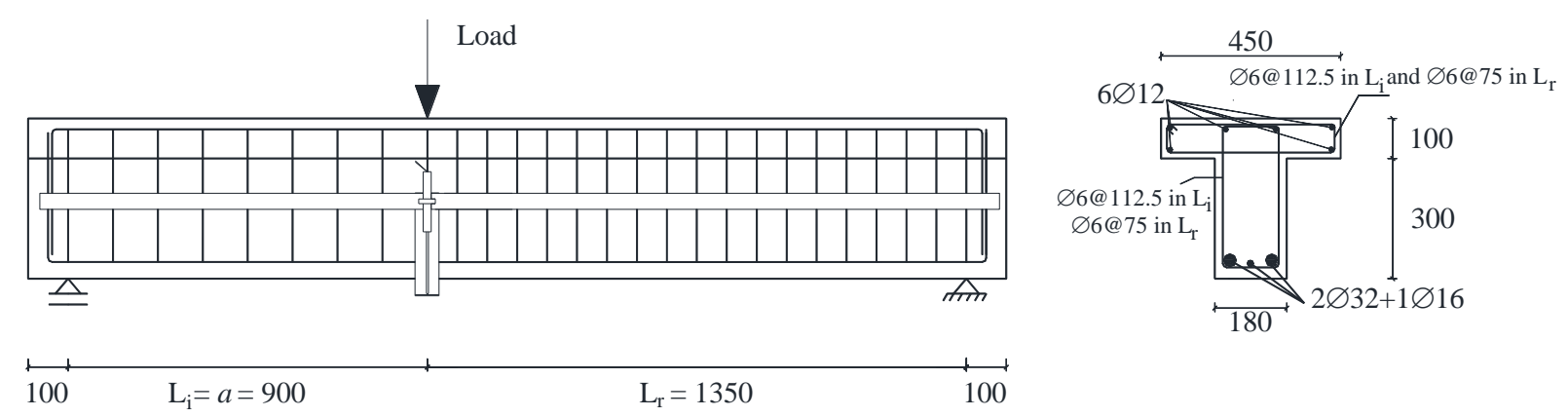

a) T-7S- $R$ beam
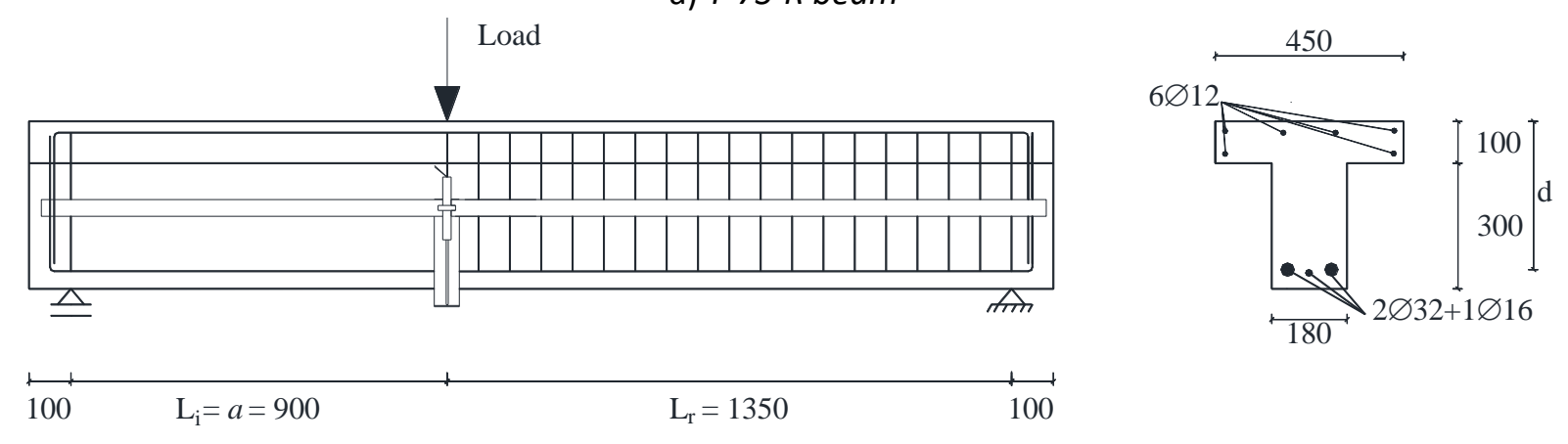

b) $T-C-R$ beam

Figure 3: Geometry, reinforcement arrangement, and location of LVDT in T cross section beams; a) T-7S-R beam;

b) T-C-R beam (dimensions in $\mathrm{mm}$ ) 


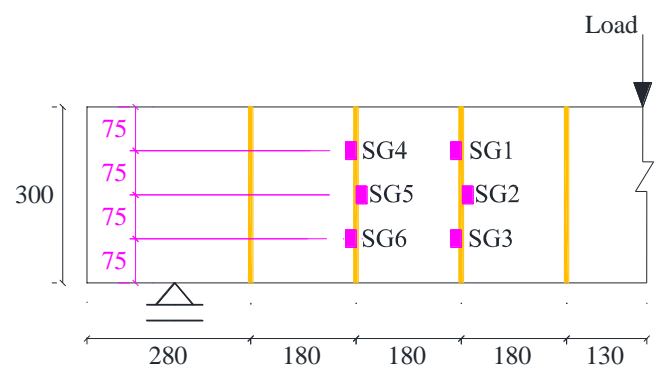

a) R-NSM-4L90

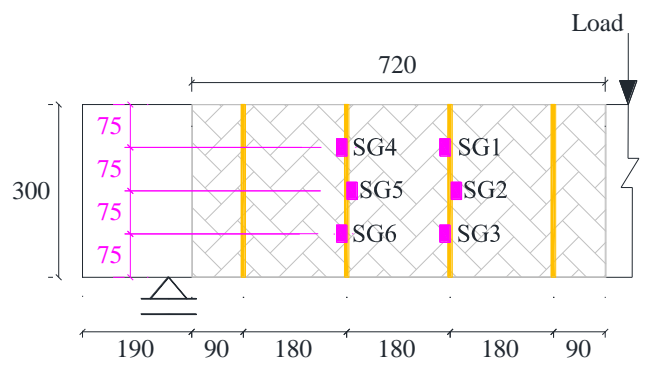

c) R-4L90

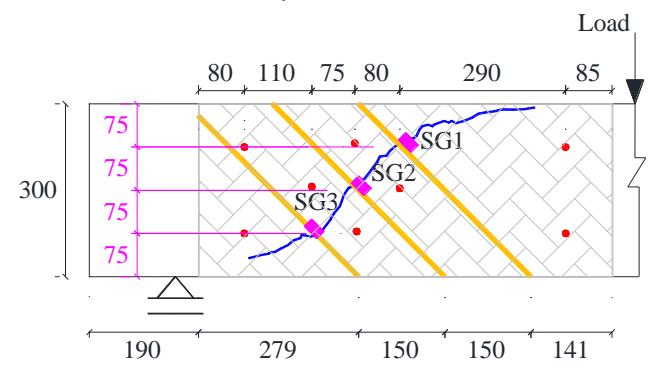

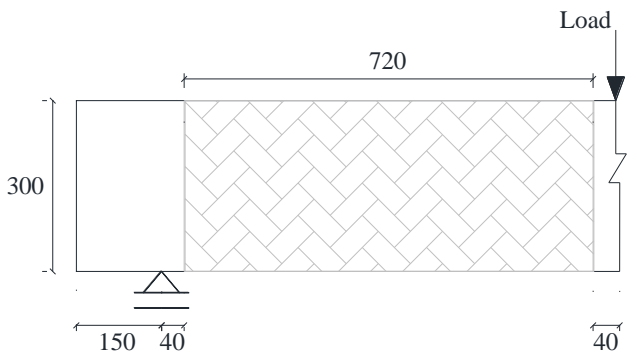

b) R-SP
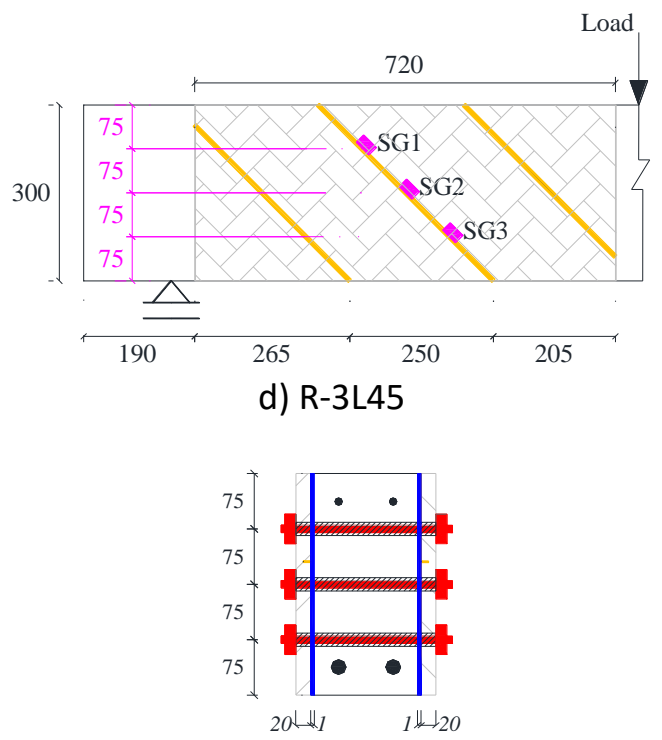

e) R-D-3L45-B

Figure 4: Geometry, shear strengthening details, and layout of strain gages for beams with a rectangular cross-section (dimensions in $\mathrm{mm}$ ) 


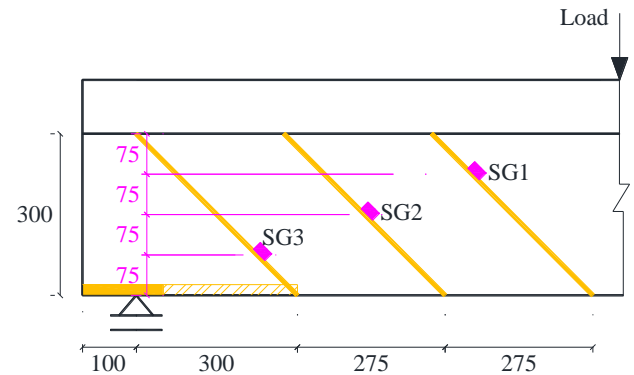

a) T-NSM-3L45
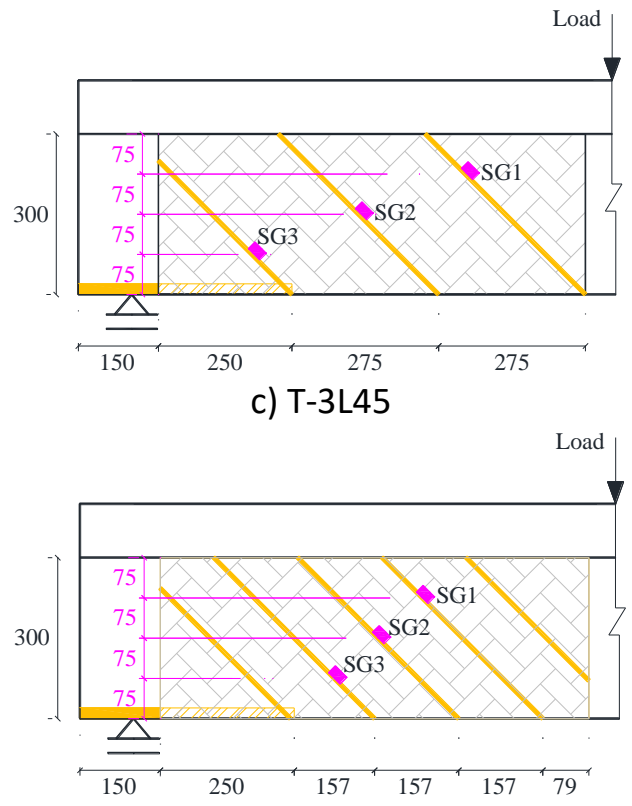

e) T-5L45

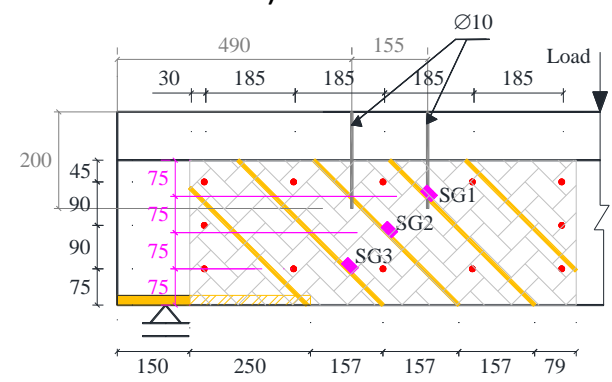

g) $T-5 L 45-B C$

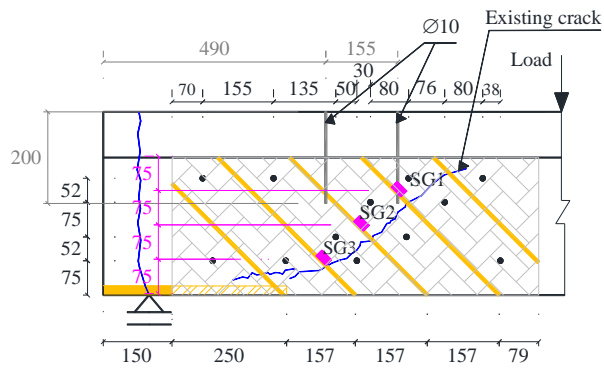

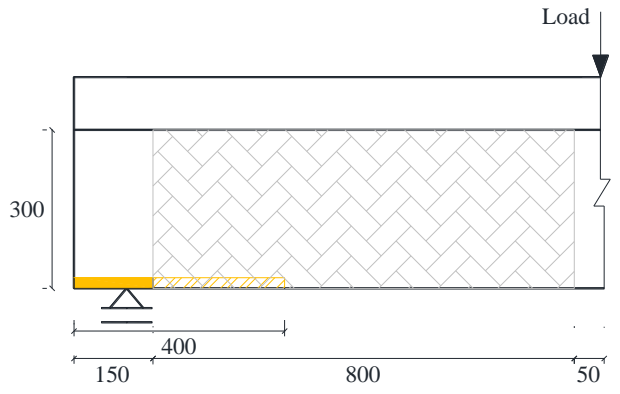

b) T-SP
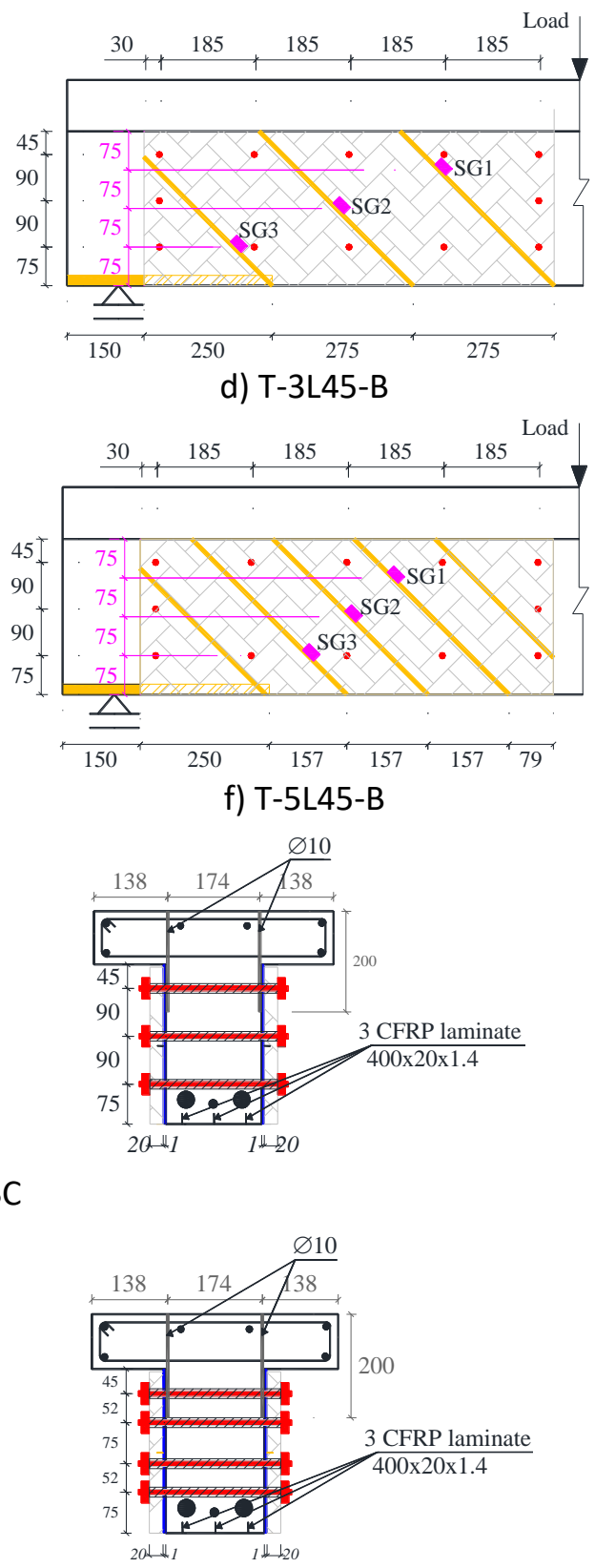

h) T-D-5L45-BC

Figure 5: Geometry, shear strengthening details, and layout of strain gages for beams with a $T$ crosssection (dimensions in $\mathrm{mm}$ ) 


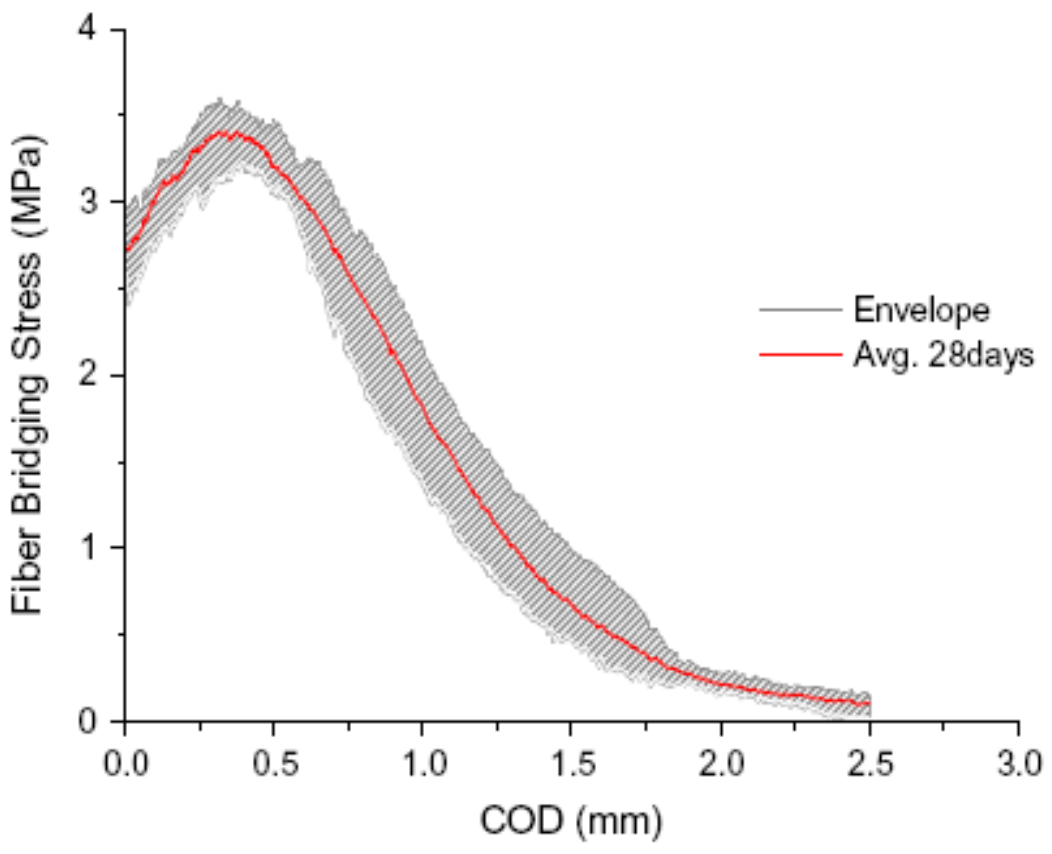

Figure 6: The envelope and the average tensile stress versus crack opening displacement (COD)obtained in notched specimens [14] 


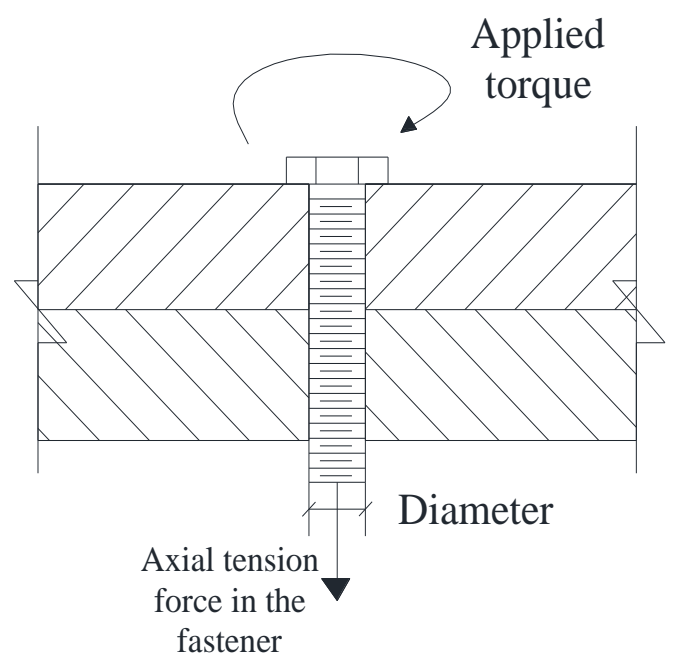

Figure 7: The relation between the applied torque to axial tension force in the fastener 


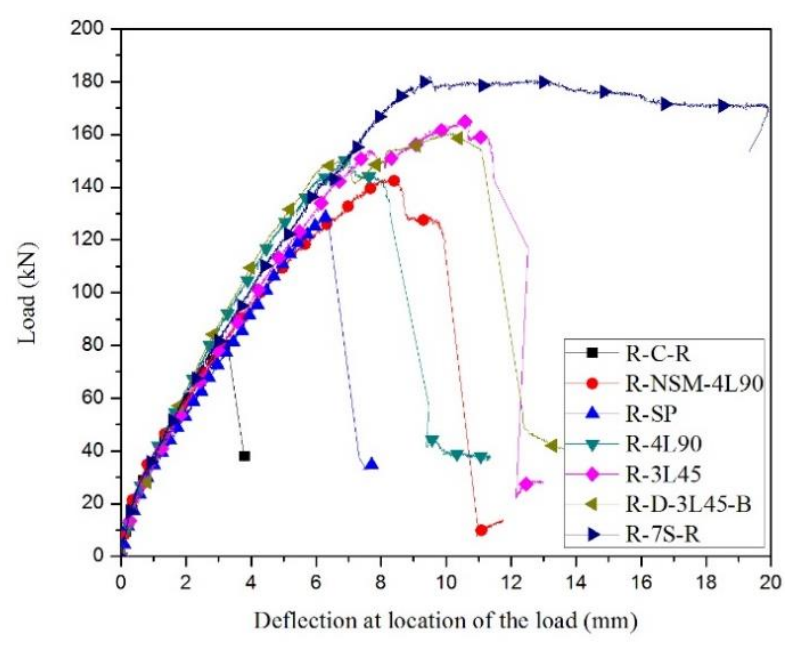

a)

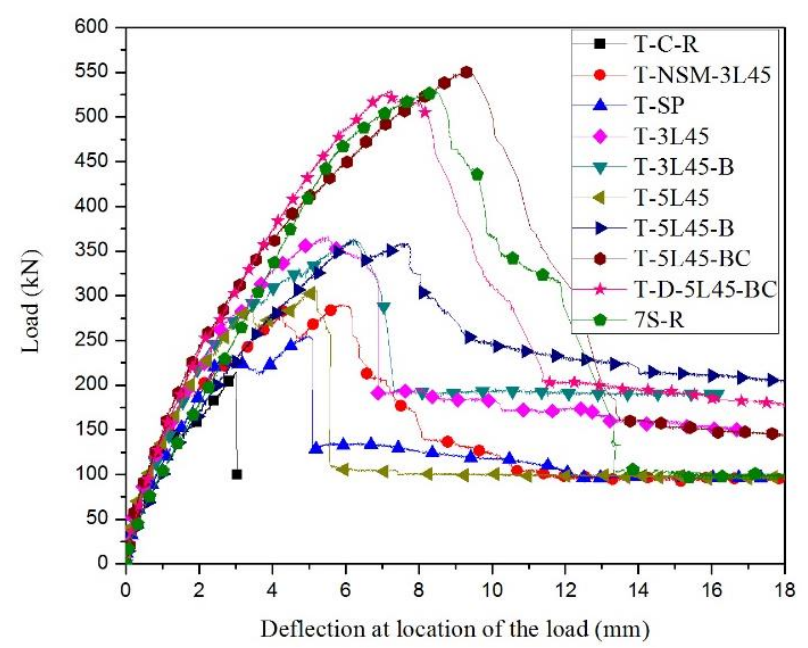

b)

Figure 8: Load vs. deflection at the loaded-section of series of: a) rectangular cross section; b) T cross section beams 


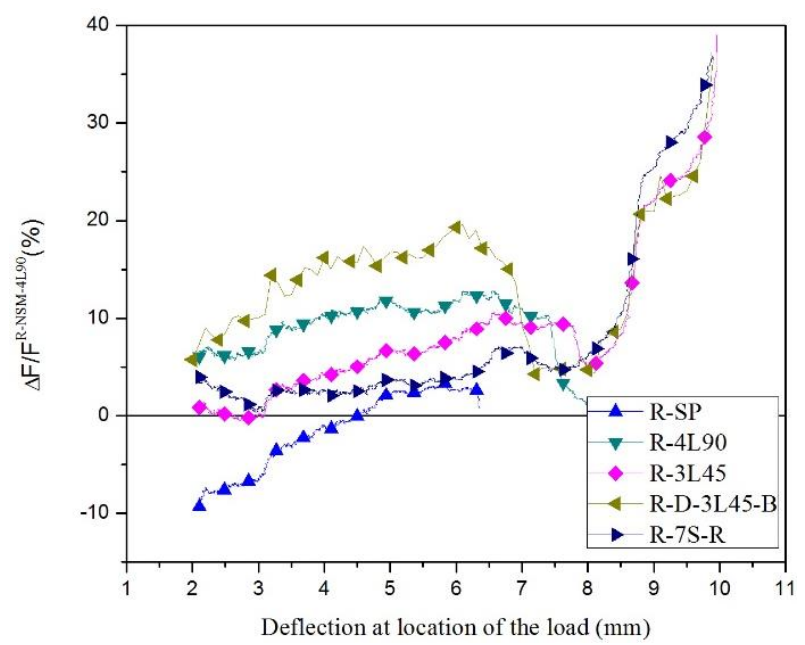

a)

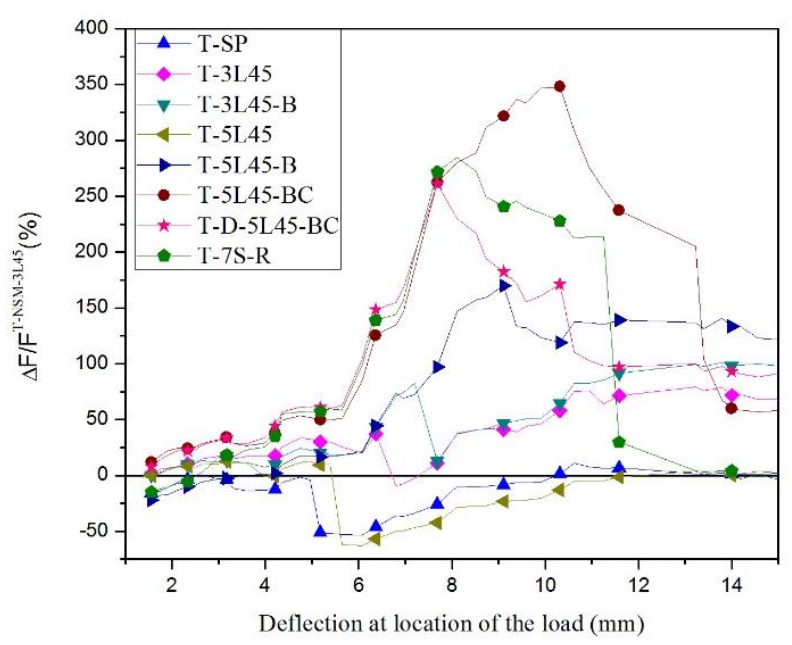

b)

Figure 9: $\Delta F / F^{N S M-3 L 45}$ vs. deflection at the loaded-section for the beams strengthened with SHCC/HCPs; a) Rectangular cross section beams; $b$ ) $T$ cross section beams 


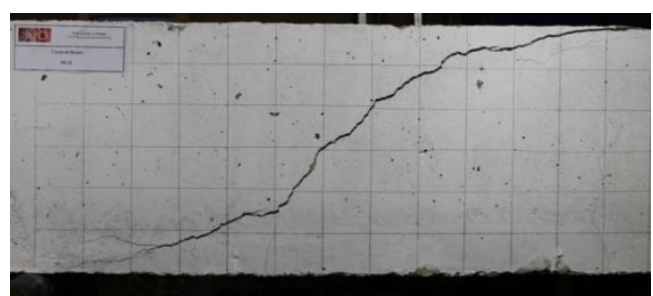

a) Crack pattern at failure load of the R-C-R beam

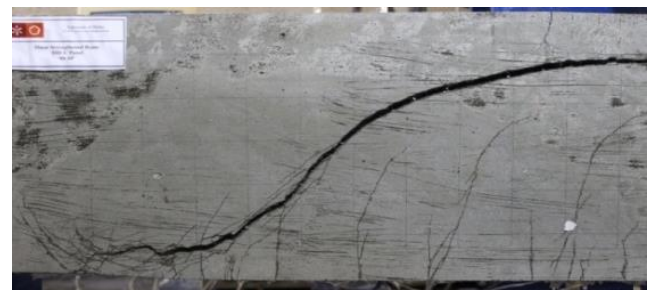

c) Crack pattern at failure load of the R-SP beam

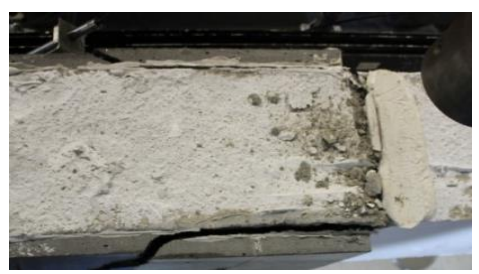

e) Detachment of the HCPs in R-SP-4L90 beam

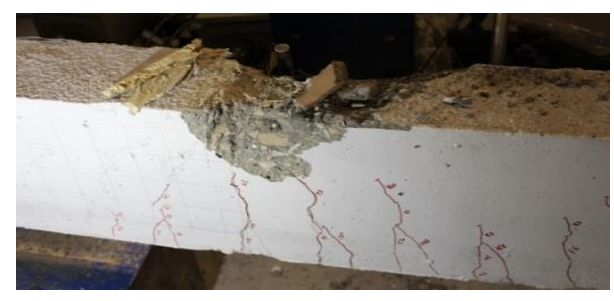

b) Crack pattern at failure load of the R-7S-R beam

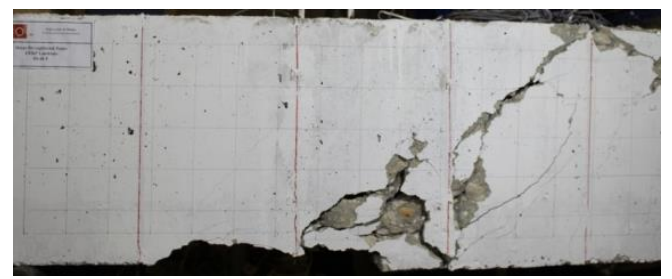

d) Crack pattern at failure load of the R-NSM-4L90 beam

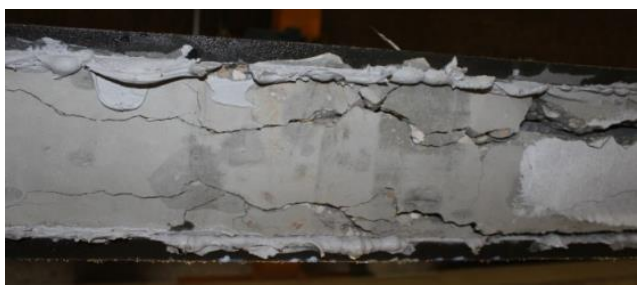

f) Crack pattern in the bottom surface at failure load of SP-3L45 beam

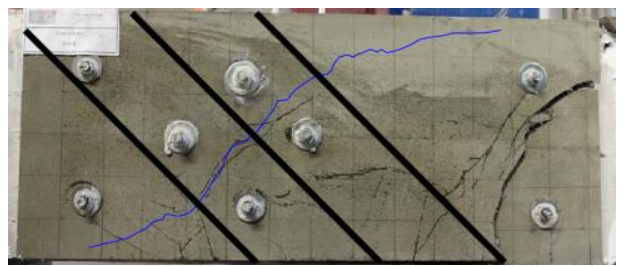

g) Crack pattern in the lateral surface of R-D-3L45-B beam at failure load

Figure 10: Crack pattern at failure of rectangular cross section beams 


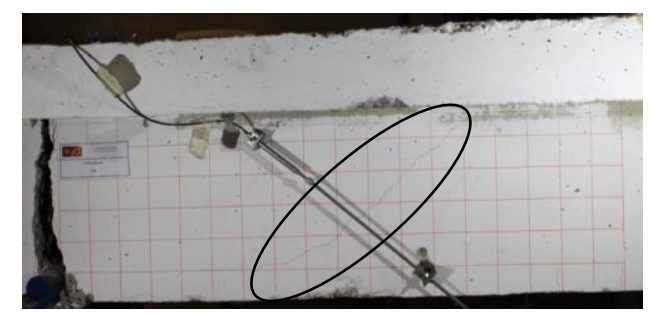

a) Crack pattern at failure load of T-C-R beam

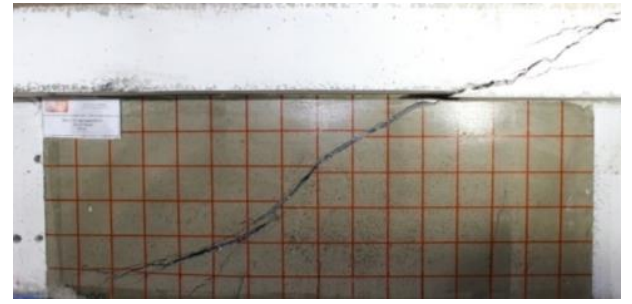

c) Final crack pattern of the T-SP beam

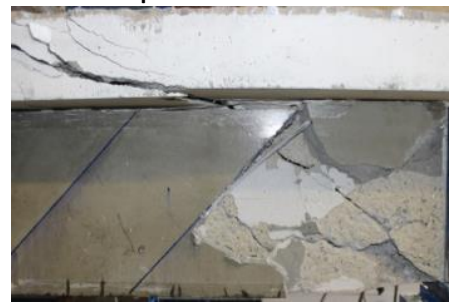

e) Local detachment of HCPs at failure load of T-

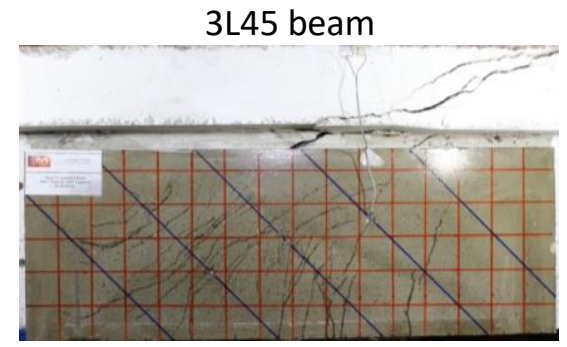

g) Final crack pattern of the $T-5 \mathrm{~L} 45$ beam

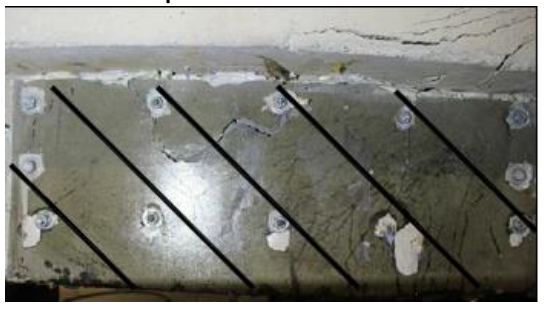

i) Crack pattern in the lateral surface of T-5L45-BC beam at failure load

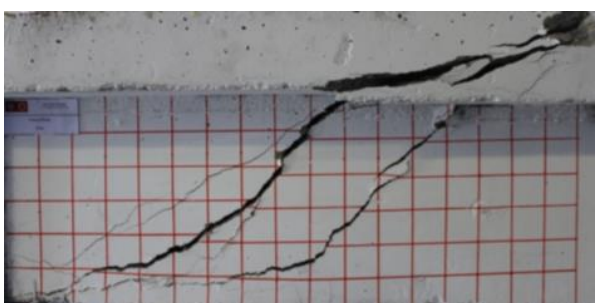

b) Crack pattern at failure load of T-7S-R beam

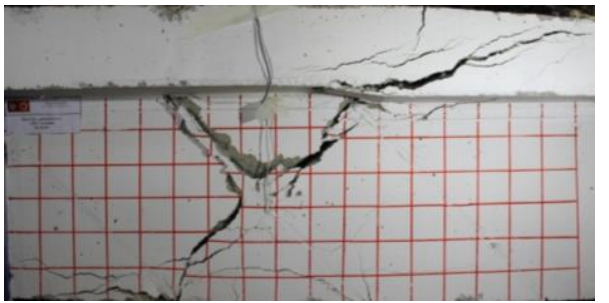

d) Final crack pattern of the NSM-3L45 beam

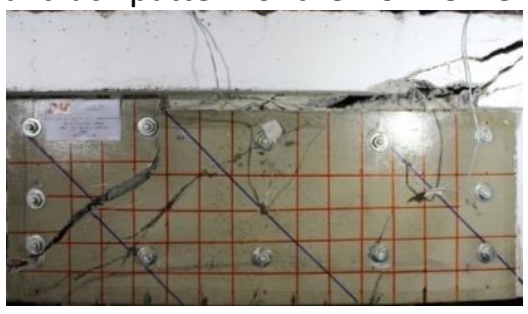

f) Final crack pattern of the T-3L45-B beam

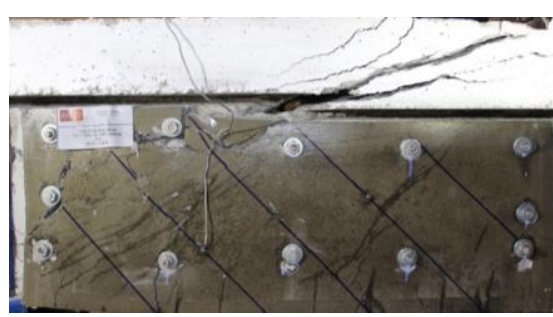

h) Final crack pattern of the T-5L45-B beam

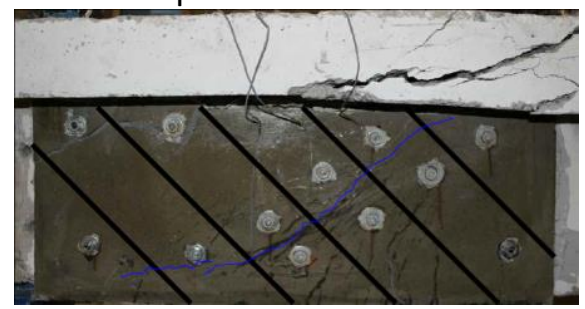

j) Crack pattern in the lateral surface of T-D-5L45$\mathrm{BC}$ beam at failure load

Figure 11: Crack pattern at failure of T cross section beams 


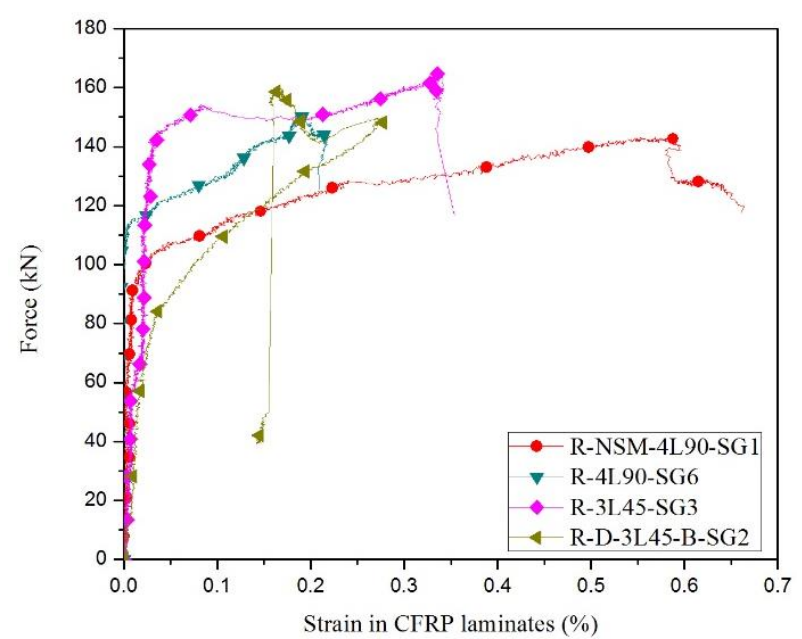

a)

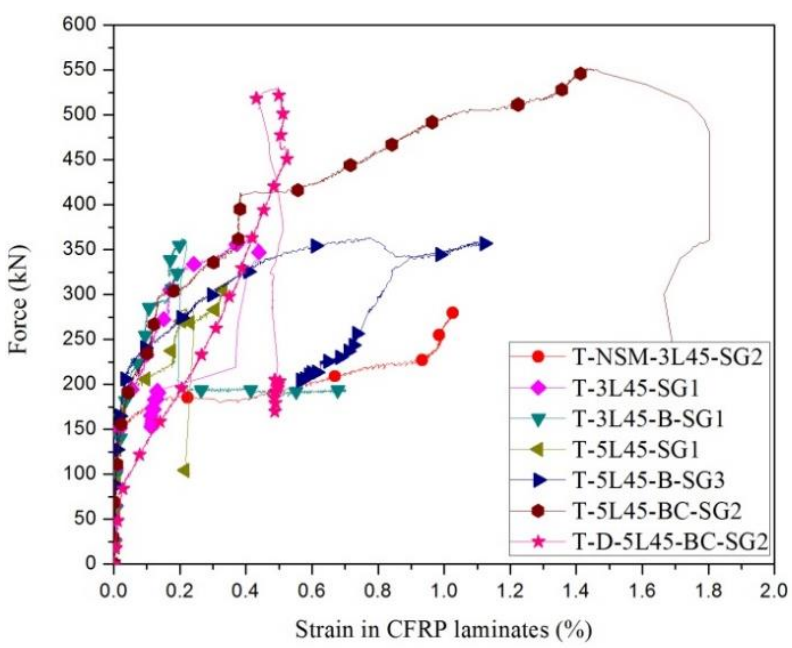

b)

Figure 12: Force vs. strain in monitored laminates in SGs where the maximum strains were registered; a) rectangular cross section beams; $b$ ) $T$ cross section beams 

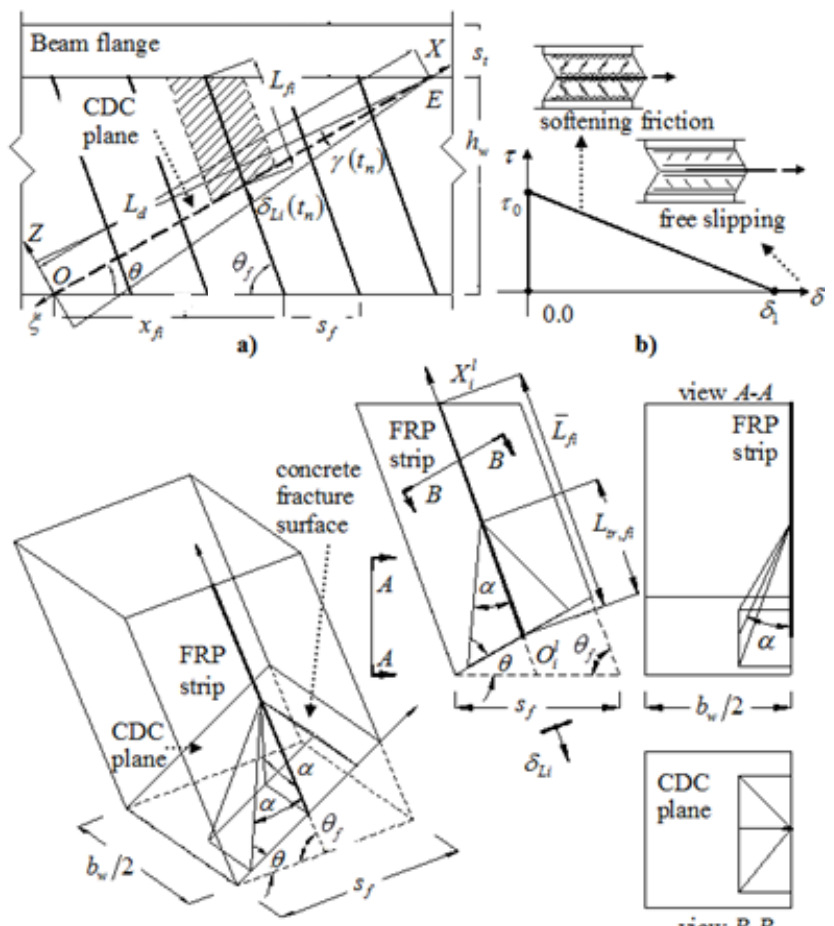

b)

c)

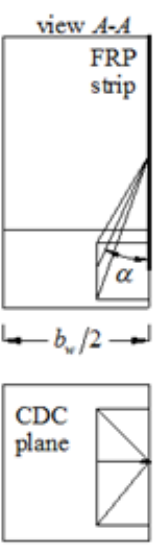

d) view $B-B$
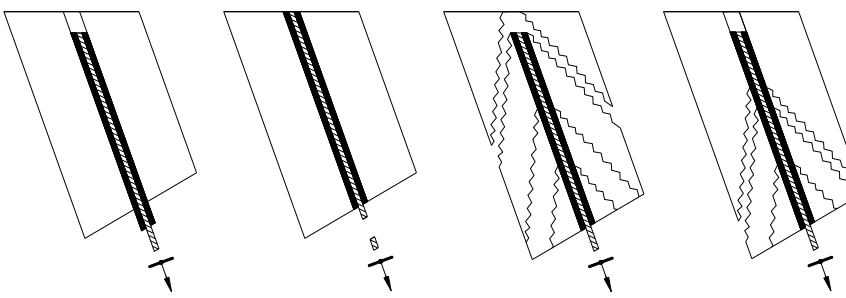

Debonding

Strip tensile rupture

Concrete semipyramidal fracture

Mixed shallowsemi-pyramid-plus-

e) debonding

Figure 13: Schematic representation of the Bianco et al. model [10]; a) average-available-bond-length NSM strip and concrete prism of influence; $b$ ) adopted local bond stress-slip relationship; c) NSM strip confined to the corresponding concrete prism of influence and semi-pyramidal fracture surface; $d$ ) sections of the concrete prism; e) The mode of failure of an NSM FRP laminate subjected to an imposed end slip. 


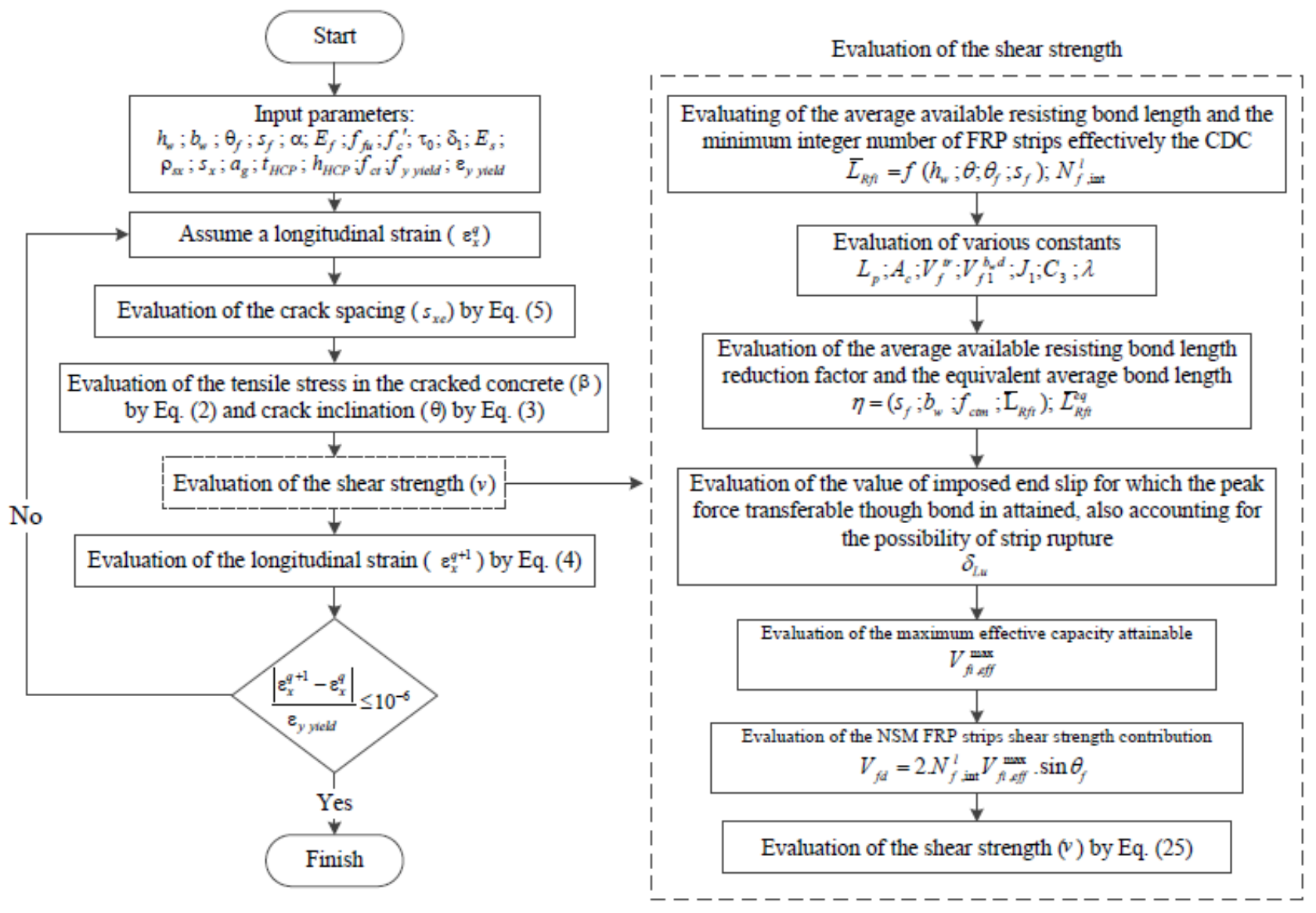

Figure 14: Calculation procedure of BSMCFT adapted to HCP technique 


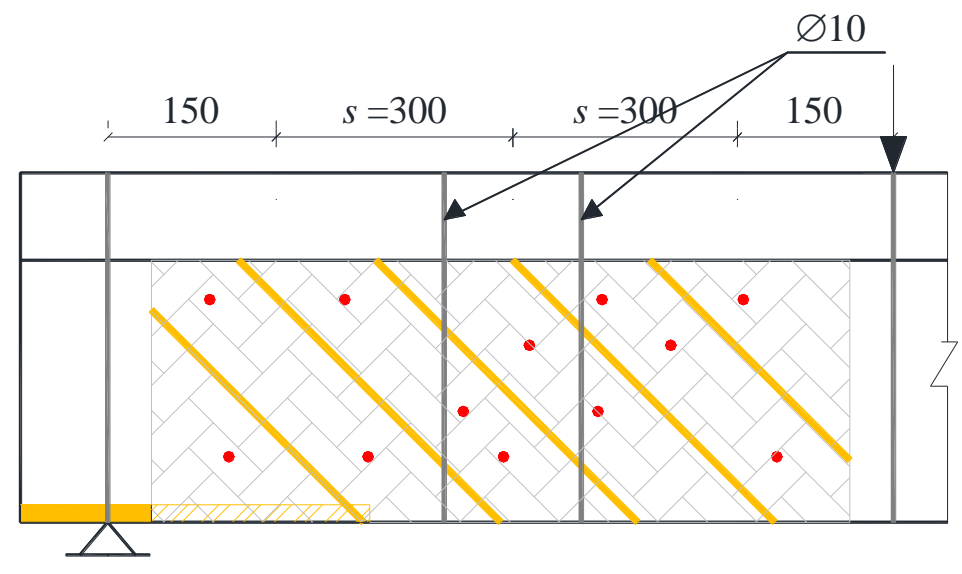

2 Figure 15: Equivalent distance between steel stirrups $(s)$ in the T-D-5L45-BC and T-5L45-BC beams 3 